\title{
Sur le polymorphisme de l'Ankistrodesmus Braunii (Naegeli) Collins.
}

Etude de planctologie expérimentale par W. Vischer.

Ce travail est le résultat de quelques expériences sur le polymorphisme de l'Ankistrodesmus Braunii ( $\mathrm{N}$ a e geli) Collins ${ }^{1}$ (Rhaphidium Braunii Naegeli²). Son but fut; de constater comment cette algue unicellulaire, réagit vis-à-vis d'influences extérieures, quẹ est son polymorphisme et quelles sont les conditions exactes qui provoquent telle ou telle forme.

J'avait fait part à Monsieur le professeur Chodat de mon désir de me perfectionner dans les méthodes de culture d'algues; je tiens à le remercier tout particulièrement de m'avoir proposé un sujet si intéressant. Il a aussi aimablement mis à ma disposition une culture pure de l'Ankistrodesmas Braunii ( $\mathrm{N}^{0} 153$ de la collection centrale des cultures pures conservées à l'Institut de Botanique de l'Université de Genève). En même temps je lui exprime tous mes remerciements pour ses précieux conseils, basés sur une longue et fructueuse expérience, qui ont beaucoup facilité le commencement de mon travail.

Au cours de mes recherches, je fus attiré par le problème de la flottaison et je commençai qeulques expériences; mais les circonstances ne me permirent pas de les continuer. Si je présente au lecteur les résultats fragmentaires de mon travail, c'est, parceque pendant plusieures années, il me sera impossible de les compléter.

Nous employons les mots "polymorphisme" et "polymorphe“ ou "pléomorphe" dans le sens de Chodat: „Polymorphisme est un terme descriptif qui n'implique aucune théorie particulière et qui énonce simplement qu'une même plante peut se présenter sous plusieurs aspects". ${ }^{3}$ "C'est une propriété que possèdent certaines espèces de revêtir des formes différentes

\footnotetext{
1 Collins, 78 (1912); Brunnthaler, 189 (1915).

${ }^{2}$ Kützing. 891 (1849).

3 Chodat, 143 (1909).
} 
sans changer de nature. “ ${ }^{1}$ "Il n'y a pas de théorie du poly. morphisme, il y a des algues polymorphes".5 L'auteur insiste encore sur le fait que certaines algues sont remarquablement plastiques ou polymorphes, tandisque d'autres, voir la plupart, sont très stables et uniformes. Dans tous les travaux modernes, c'est à dire dans tous ceux dont le point de départ étaient des cultures pures, le terme "polymorphisme" est employé dans ce sens. Il est donc inutile d'insister sur la différence entre cet emploi parfaitement clair et net, et entre la vieille conception transformiste qui appartient à l'histoire.

Dans ses deux grands travaux classiques, ${ }^{6}$ Chodat a essayé de décrire l'amplitude du polymorphisme pour un très grand nombre d'espèces; il s'agit maintenant de constater d'une façon exacte quelles sont les conditions qui, chez chaque espèce, déterminent l'apparition de chaque morphose. Pour la bibliographie et l'histoire de ces recherches, nous renvoyons le lecteur aux deux ouvrages déjà cités de Chodat et au travaux récents de Küfferath, RayB et Nakano. Pour compléter ces listes, nous n'avons qu'à ajouter les derniers travaux de Chodat, Großmann, Harder, Issatschenko, Kuwada, Lieske. Limberger, Prat, Schramm, Senn et $\mathrm{S}$ mith. Ce dernier a appliqué la méthode des cultures pures à l'étude monographique d'un genre (Scenedesmus).

Nous pouvons dire qu'aucun fait n'a été cité qui ait montré l'inexactitude d'une observation décrite par Chodat dans un des deux travaux mentionnés. La critique de Richter, ${ }^{7}$ que les conclusions de Grintzesco et Chodat sont erronnées, n'est basée que sur une lecture tellement incomplète et mal comprise des auteurs cités, qu'elle est sans objet. Une seconde critique de principe a été dernièrement formulée par West. ${ }^{8}$ „Had Chodat's pure cultures been under more natural conditions, his recently expressed views on polymorph:sme would perhaps have been even more circumscribed." Nous devons tout de suite répondre que la question à savoir si les conditions

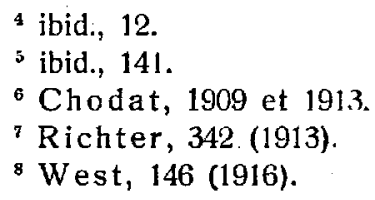


dans lesquelles on cultive les algues sont plus ou moins naturelles, n'a rien affaire avec l'existence du polymorphisme luimême. La faculté de répondre à différents milieux par des formes différentes, est une faculté innée et héréditaire de l'organisme. Cette faculté est simplement rendue visible par les différent; milieux et se manifeste uniquement selon les lois naturelles de l'hérédité. Il est donc inutile d'insister sur cette critique dont les principes rendraient impossible toute recherche physiologique. West dit apropos des cultures pures: „It is sometimes desirable, especially if pure cultures are required, to begin with one or two individuals".9 II va sans dire qu'une véritable culture pure doit dériver d'un seul germe, et que c'est un' point qui n'est pas seulement désirable, mais essentie'.

Nous avons donc le droit d'employer le terme „polymorphisme" dans le sens indiqué. Les cellules de l'Ankistrodesmus Braunii sont - en solution Detmer $\frac{1}{3}-$ allongées, droites ou légèrement en forme de $S$, fusiformes, longues de $35-50 \mu$, larges de $5-8 \mu$, atténuées aux extrémités. Le chromatophore est une plaque pariétale, en général recourbée aux bords, souvent avec une échancrure au milieu, jamais avec pyrénoïde. La multiplication se fait par division transversale du contenu; les cellules filles s'allongent en autospores et ceci fait paraître le flan de la segmentation oblique ou même parallèle (Fig. $5,7-11$ ) au grand axe. La parois de la cellule mère se déchire dans le plan équatorial en deux moitiées en forme de coiffe, et les cellules filles sont libérées. Dans tous les cas où nous avons pu l'observer, la rupture s'est produite de la même façon. Il existe donc une différence fondamentale, connue depuis longtemps, ${ }^{1(1}$ entre ce mode de multiplication par autospores et le vrai cloisonnement qu'on observe chez le Protococcus viridis Ag. (Pleurococcus vulgaris auct.) (rapproché de nouveau à tort des Cystosporacées [Protococcacées] par West11.

$\mathrm{Si}$ nous laissons de côté les travaux transformistes (voir la liste dans $\mathrm{Chodat}$, Polymorphisme des Algues), les formes suivantes de l'Ankistrodesmus Braunii ou d'espèces voisines ont été décrites:

\footnotetext{
'West, l. c. p. 144.

${ }^{10}$ Chodat, 609 (1994, II).

11 1. c. (1916).
} 
I. K leb s${ }^{12}$ décrit des spores remplies d'huile; mais il n'est pas possible, d'après la description très courte, de se faire une idée exacte de la forme observée.

2. Chodat et Malinesco13 décrivent des formes irrégulières du Rhaphidium Braunii qu'ils ont observées dans une culture sur une assiette.

3. Chodat ${ }^{14}$ décrit des arbuscules ${ }^{15}$ fixés sur des algues filamenteuses, et des cellules isolées, fixées comme un Sciadium.

4. Le même auteur ${ }^{16}$ décrit la formation d'une ou de plusieures spores arrondies qui restent entourées pendant un certain temps par la parois incolore et souvent encore fusiforme de la cellule mère. Les observations de $\mathrm{Cho}$ dat sont critiquées par $\mathrm{Klebs}^{17}$.

5. Artari ${ }^{18}$ décrit la formation de spores allongées, pointues, remplies de carotine et de gouttelettes d'huile, et qui germent après un temps de repos.

6. C'est Chodat qui, le premier, a pris des Ankistrodesmus en culture pure.19 L'Ankistrodesmus Braunii se développe facilement sur l'agar avec Detmer, sur milieu glucosé, mais craint la peptone. Il montre un polymorphisme très prononcé et forme des cellules fusiformes, allongées, arrondies ou irrégulières. Souvent une division multiple a lieu à l'intérieur de la cellule mère et on observe alors un pseudoparenchyme et des formes chlorelloïdes. L'Ankistrodesmas faícatus (Corda) Ralfs. et l'Ankistrodesmus minutus ( N a eg.) Chod. diffèrent de l'A Braunii par des caractères morphologiques et physiologiques (1. c., 98). Ces études sont complétées plus tard. ${ }^{20}$

${ }^{13}$ 'Klebs, 333 (1881-85).

${ }^{13}$ Chodat et Malinesco, 640 (1893).

${ }^{14}$ Chodat, $609(1894$, II) et $2(1894$, I).

${ }^{15}$ Plús tard, 168, 199 (1902), le même auteur attribue cette forme à $l$ ' $A n$ kistrodesmus falcatus (Corda) Ralfs (Rhaphidium fasciculatum Kützing, dont elle constitue une variété; voir aussi Brunnthaler, 188 (1916).

${ }^{16}$ Chodat, 109 (1895).

17 Klebs, 174 (1896).

18 Artari, (1892).

19 Chodat, 94 (1909).

${ }^{20}$ Chodat (1913) et Hoffmann-Grobéty (1912). 
8. Citons encore les formes de l'Ankisdrodesmus Chodati ( Tanner-Füllemann) B runnthaler.21 Cette espèce diffère de l'A. Braunii par la présence d'un pyrénoïde; mais elle montre une analogie morphologique par la formation de stades pseudoparenchymateux, qui rappellent certaines formes décrites de l'A. Braunii.

Les observations $\mathrm{I}-5$ sont faites sur un matériel impur. L.es auteurs cités sont les premiers à exiger que leurs recherches soient vérifiées par l'expérience à partir de cultures pures; mais il sera toujours difficile ou impossible de savoir, si on a affaire à la même race qu'un auteur antérieur.

Il s'agissait donc, dans nos recherches, d'obtenir si possible, à partir d'une culture pure issue d'un seul germe, toutes ou au moins une partie de ces formes mentionnées; il fallait en outre essayer d'établir les conditions exactes qui sont nécessaires pour chacune d'elles. Comme, par sa forme allongée, l'Ankistrodesmus s'éloigne beaucoup des genres voisins, il était intéressant de savoir s'il est aussi capable de former un stade "Dactylococcus"; ceci serait une nouvelle preuve pour son affinité avec les Scenedesmus.

Les travaux qui nous servaient plus particulièrement comme point de départ étaient ceux déja cités de Grintzes co o ${ }^{22}$ et $\mathrm{Chodat}$ sur les Scenedesmus et les Ankistrodesmus et celui do Ray $B^{23}$ sur le Coelastrum proboscideum. Cette dernière algue se rencontre le plus souvent en colonies; la formation de celles-ci est facilitée ou empêchée selon le milieu. L'Ankistrodesmus Braunii est ordinairement isolé; c'est donc la forme même de la cellule qui subit une transformation. Chodat ${ }^{24}$ a constaté que sur agar avec Detmer $\frac{1}{10}$ l'algue se développe lentement et pâlit rapidement; sur agar avec $D \frac{1}{3}$, elle reste verte; l'addition de glucose accélère beaucoup le développement : en quatre mois, l'algue forme. de gros disques épais, assez brillants qui sont verts au commencement et brunissent ensuite. L'addition de peptone à la solution Detmer semble ralentir la croissance. Dans le milieu Detmer sur agar, le polymorphisme est con-

\footnotetext{
21 Tanner-Füllemann, 156 (1906).

22 Grintzesco (1902).

29 Rayss (1915).

24 Chodat, 130 (1913).
} 
sidérable; par addition de glucose, il devient excessif. Nous ne pouvons que confirmer ces observations.

Dans nos recherches, nous avons, comme $R$ a y $B$, employé des milieux liquides. Les conditions sont, pour tous les individus, évidemment plus uniformes que sur l'agar. La solution de problèmes de planctologie expérimentale est liée à l'emploi de milieux liquides. Nous avons fait varier la concentration de la solution Detmer, de $\mathrm{Na} \mathrm{Cl}$, de Glucose, de Galactose, de Peptone; nous avons fait des essais avec ou sans addition de o,or $\%$ de $\mathrm{Fe}_{2} \mathbf{C l}_{6}$ ou de $\mathbf{M n S O}$. Nous avons employé du Detmer $\frac{1}{20}, \frac{1}{10}, \frac{1}{3}$; des solutions de Peptone de $0,05-0,5 \%$, des concentrations de $\mathrm{NaCl}$ de $0, \mathrm{I}-3,0 \%$ et des concentrations équimoléculaires de Glucose et de Glactose.

Le tableau suivant permet de comparer (sur chaque ligne horizontale) les concentrations exprimées en $\%$ et en fractions de solution normale.

\begin{tabular}{|c|c|c|c|c|c|}
\hline $\mathrm{Na} \mathrm{Cl}$ & $\begin{array}{c}\text { Glucose et } \\
\text { Galactose }\end{array}$ & $\begin{array}{c}\text { Saccha- } \\
\text { rose }\end{array}$ & \multicolumn{2}{|c|}{ Solution normale } \\
\hline $0,1 \%$ & $0,3 \%$ & & $\frac{\mathrm{N}}{60}$ & 0,0166 \\
\hline $0,2 \%$ & $06 \%$ & & $\frac{\mathrm{N}}{30}$ & 0,0333 \\
\hline $0,5 \%$ & $1,5 \%$ & & $\frac{\mathrm{N}}{12}$ & 0,0833 \\
\hline $1,0 \%$ & $30 \%$ & & $\frac{\mathrm{N}}{6}$ & 0,1666 \\
\hline $2,0 \%$ & $6,0 \%$ & & $\frac{\mathrm{N}}{3}$ & 0,3333 \\
\hline $3,0 \%$ & $9,0 \%$ & $17,5 \%$ & $\frac{\mathrm{N}}{2}$ & 0,5000 \\
\hline 58 & 180 & 342 & & \\
\hline
\end{tabular}

Solution $\frac{1}{1}$ Detmer (abrégé D) :=

$\mathrm{I}, \mathrm{g}$ nitrate de calcium $\mathrm{Ca}\left(\mathrm{NO}^{3}\right)^{2}$

$0,25 \mathrm{~g}$ chlorure de potassium $\mathrm{KCl}$

$0,25 \mathrm{~g}$ sulfate de magnésium $\mathrm{Mg} \mathrm{SO} 4$

$0,25 \mathrm{~g}$ phosphate monopotassique $\mathrm{KH}^{2} \mathrm{PO}^{4}$

trace Chlorure de fer $\mathrm{Fe}^{2} \mathrm{Cl}^{6}$.

Il est vrai que la pression osmotique d'une solution de $\frac{\mathrm{N}}{60}$ de glucose est inférieure $(2: 3)$ à $\frac{\mathrm{N}}{60} \mathrm{de} \mathrm{NaCl}$, puisque cette 


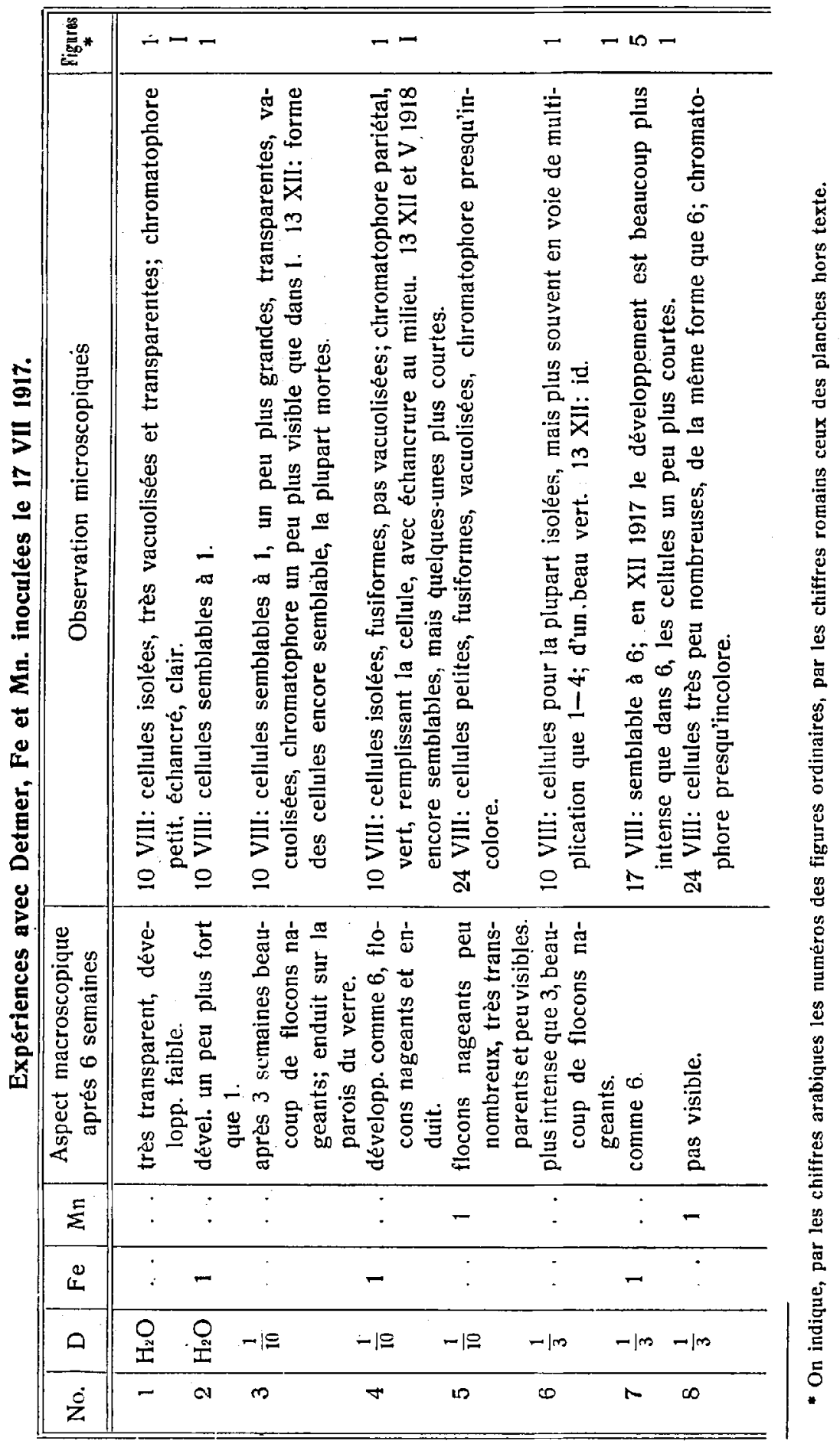




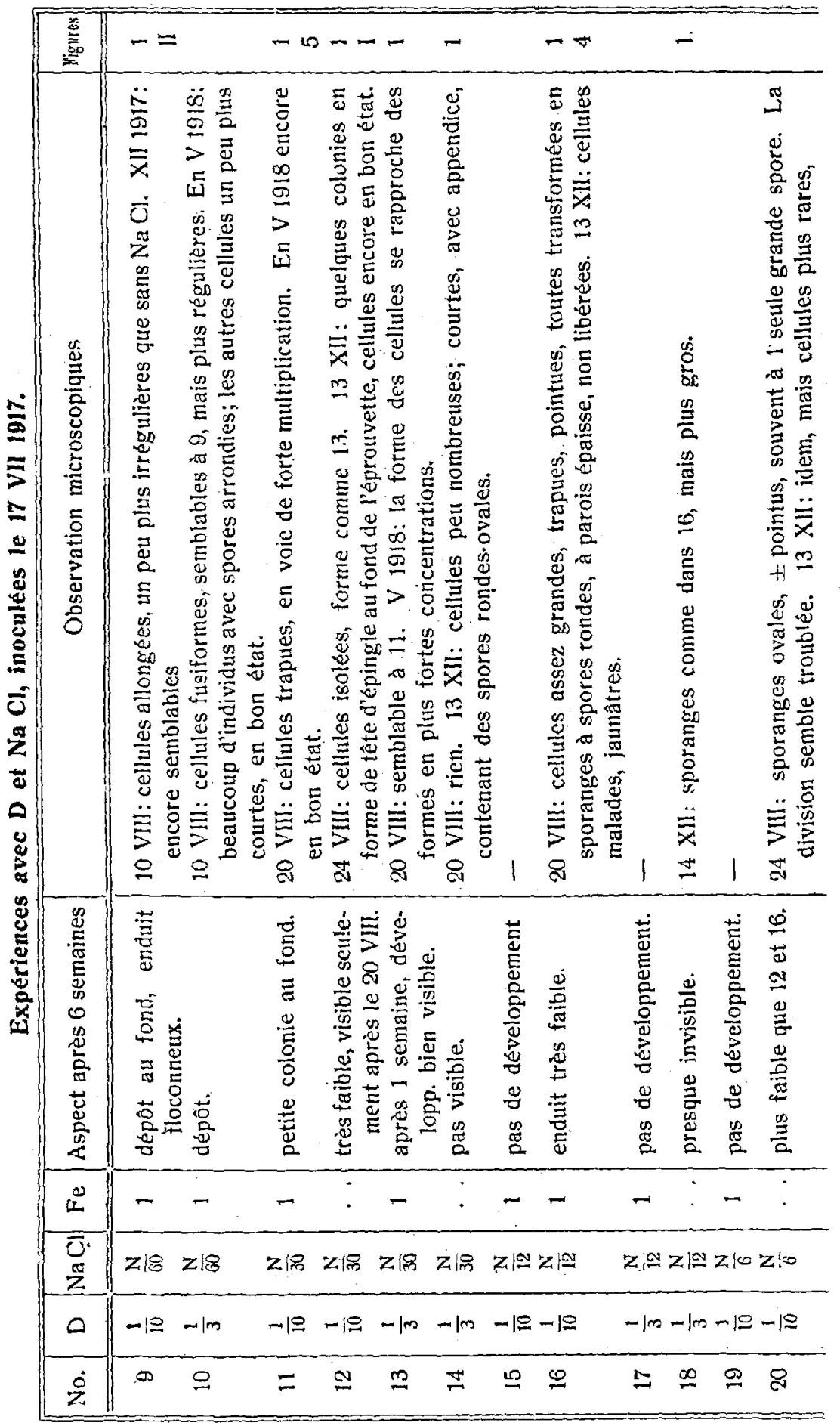




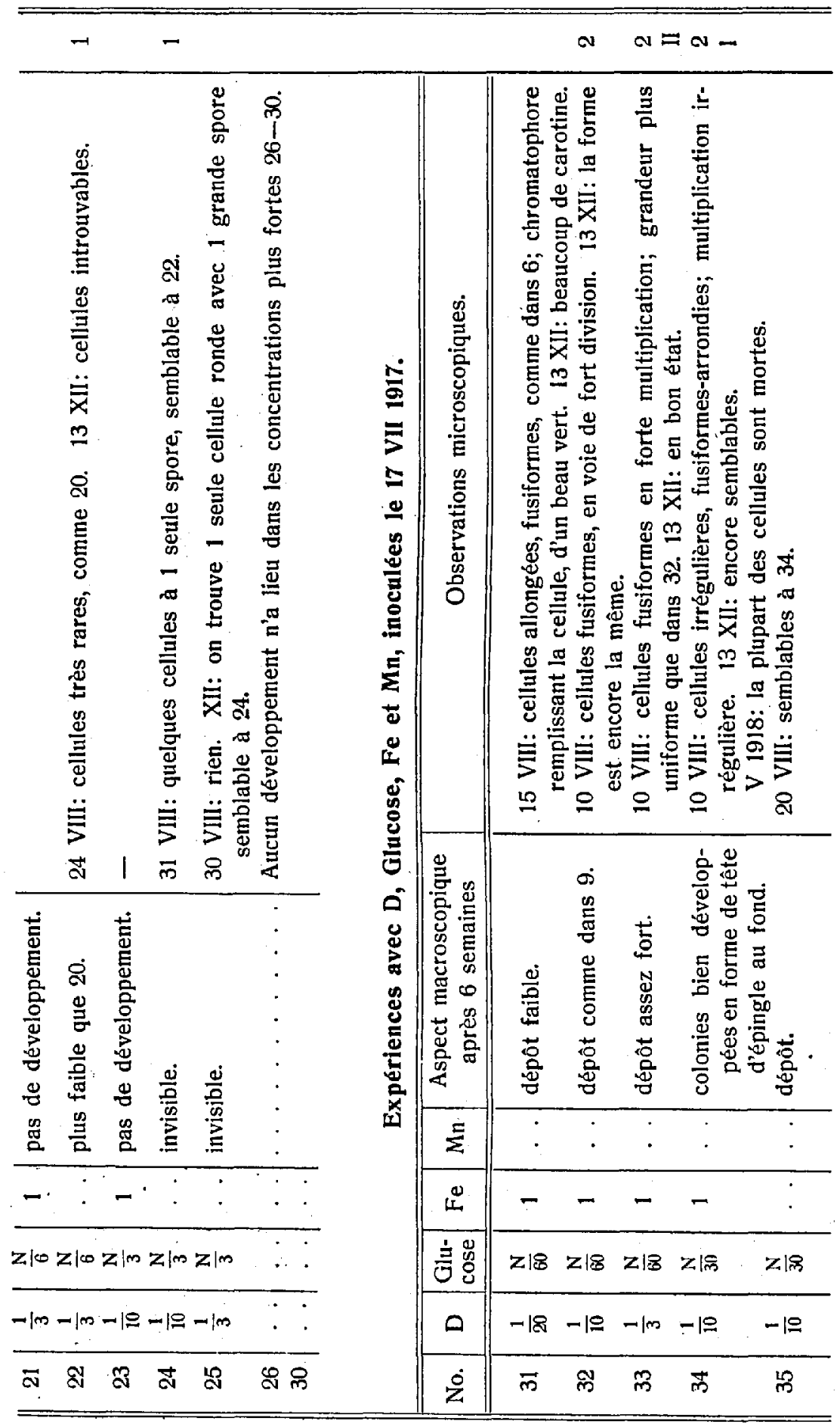




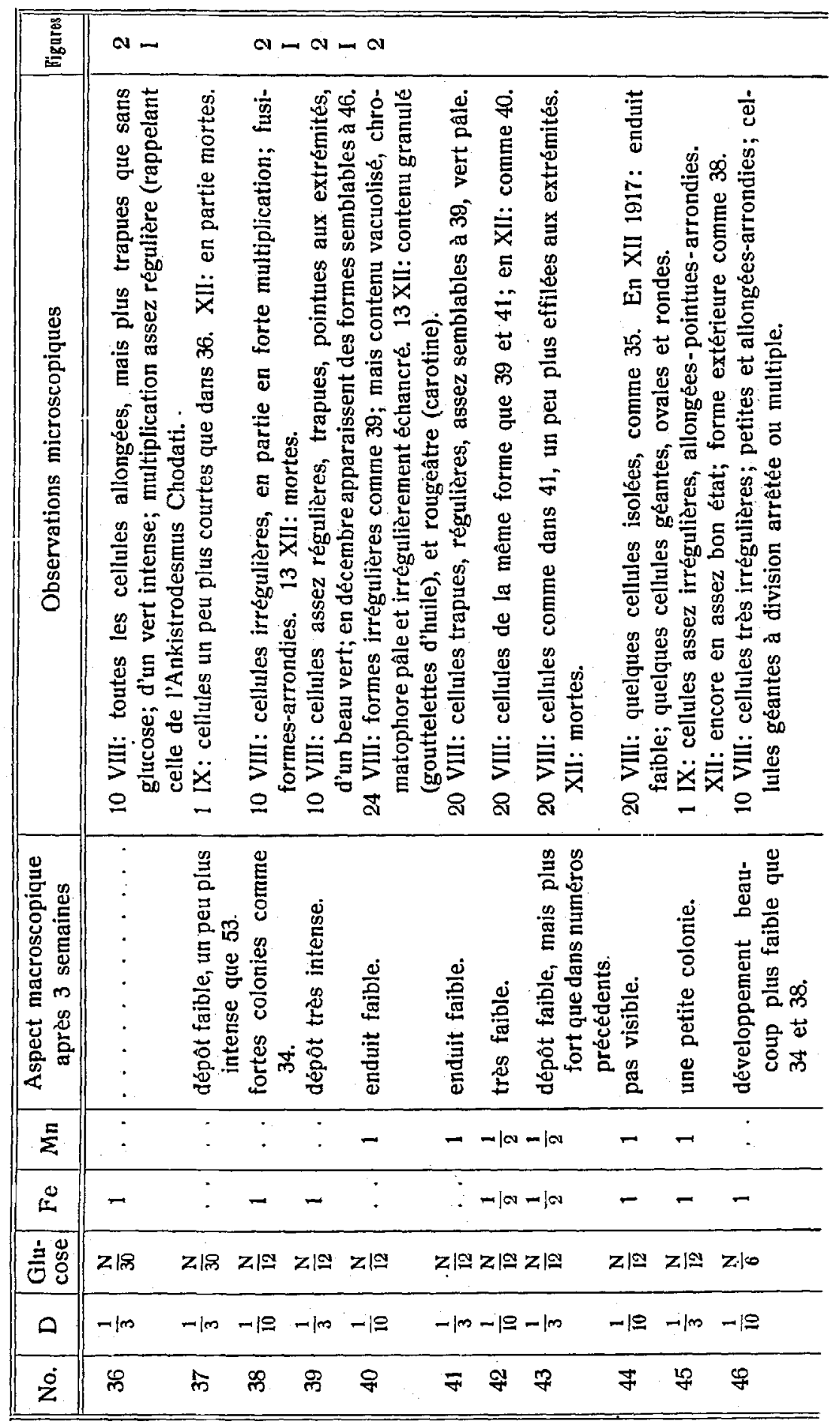


$-15-$
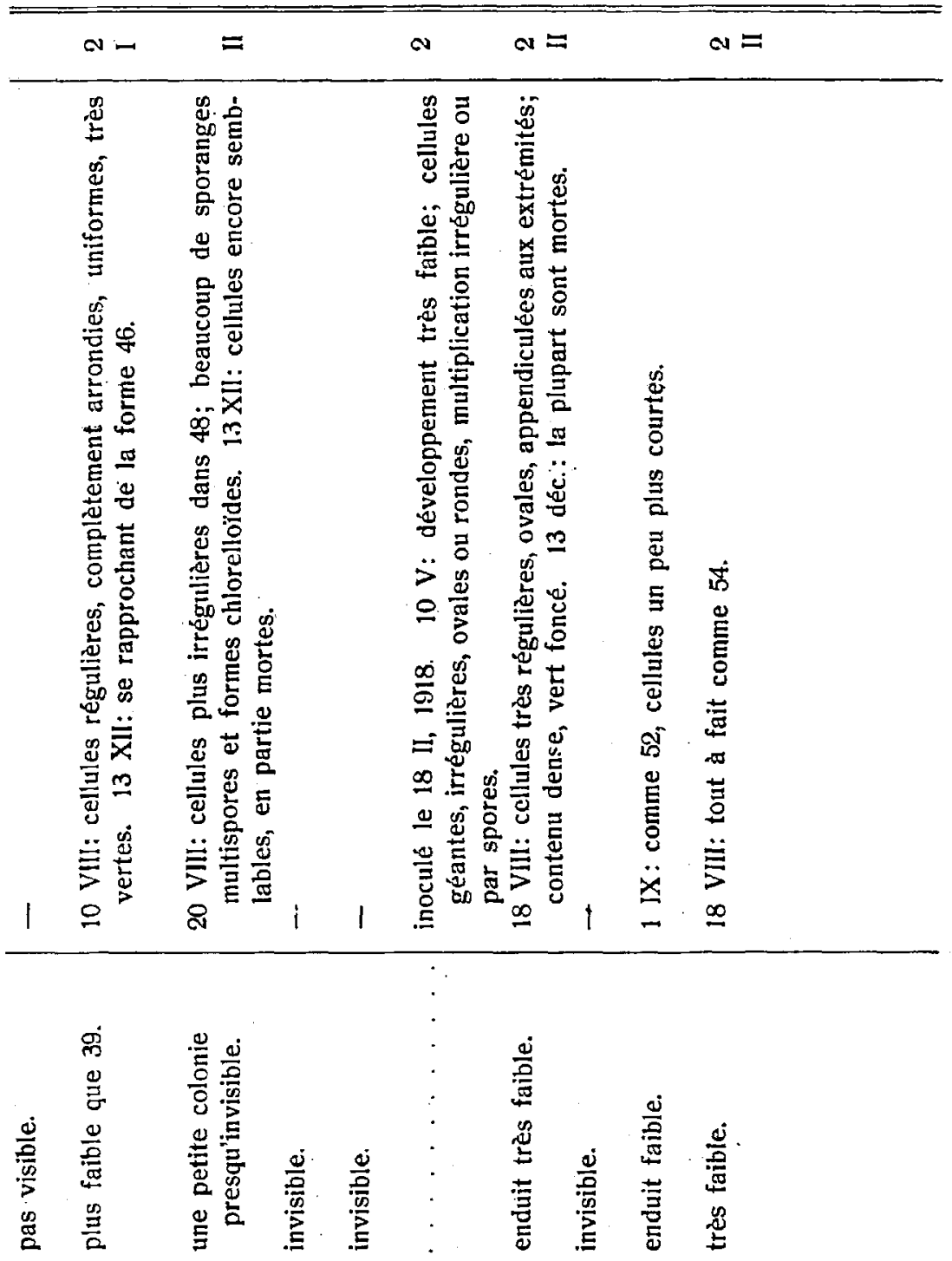

\begin{tabular}{|c|c|c|c|c|c|c|c|c|c|}
\hline : & : & . & . & : & : & . &. & $\cdot$ & . \\
\hline & & & & & & & & & \\
\hline : & - & $\therefore$ & $\rightarrow$ & -1 & - & - & $\therefore$ & - & -1 \\
\hline$z=0$ & $z \mid 0$ & $z / 0$ & $z \mid m$ & $z \mid m$ & $z \mid m$ & $z \mid a$ & $z / x$ & zio & $z|\alpha|$ \\
\hline-10 & $-1 m$ & $-1 m$ & -10 & $-\ln$ & -10 & -10 & -10 & $-\ln$ & $-1 m$ \\
\hline 与 & $\stackrel{\infty}{\sigma}$ & 8 & 8 & $\bar{\Sigma}$ & $\frac{\pi}{10}$ & ชิ่ & ஜ & 葴 & 28 \\
\hline
\end{tabular}


$-16-$

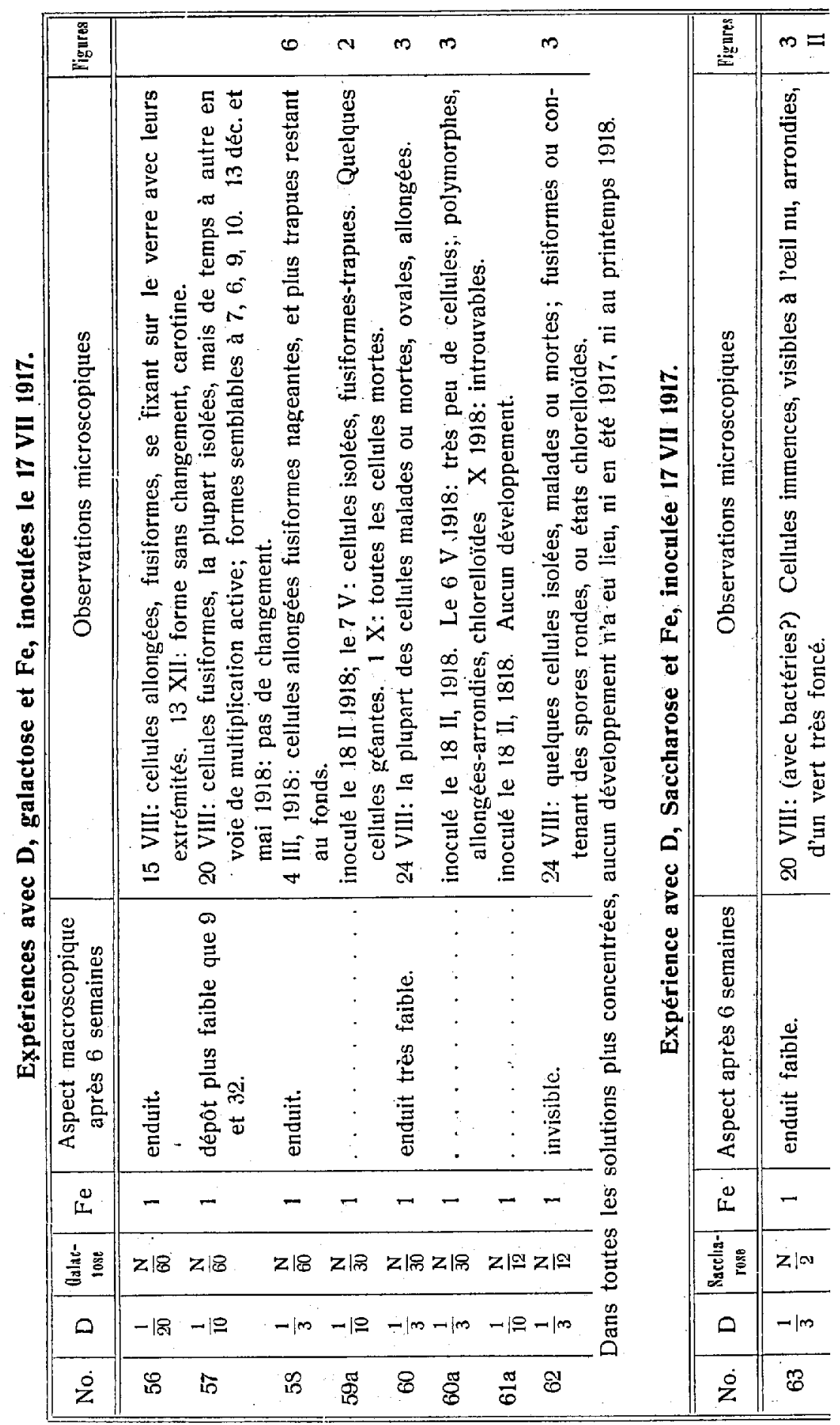




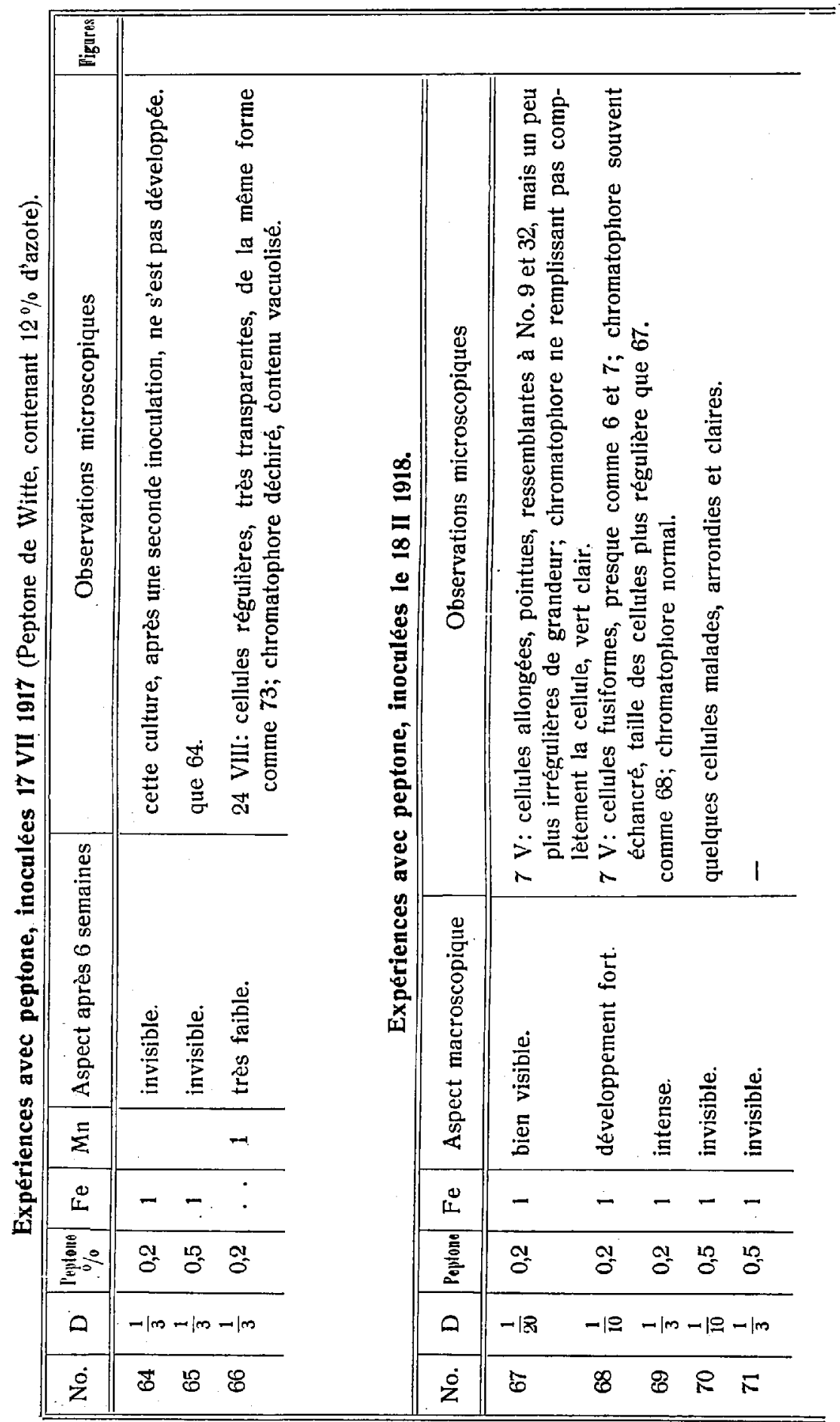


$-18-$

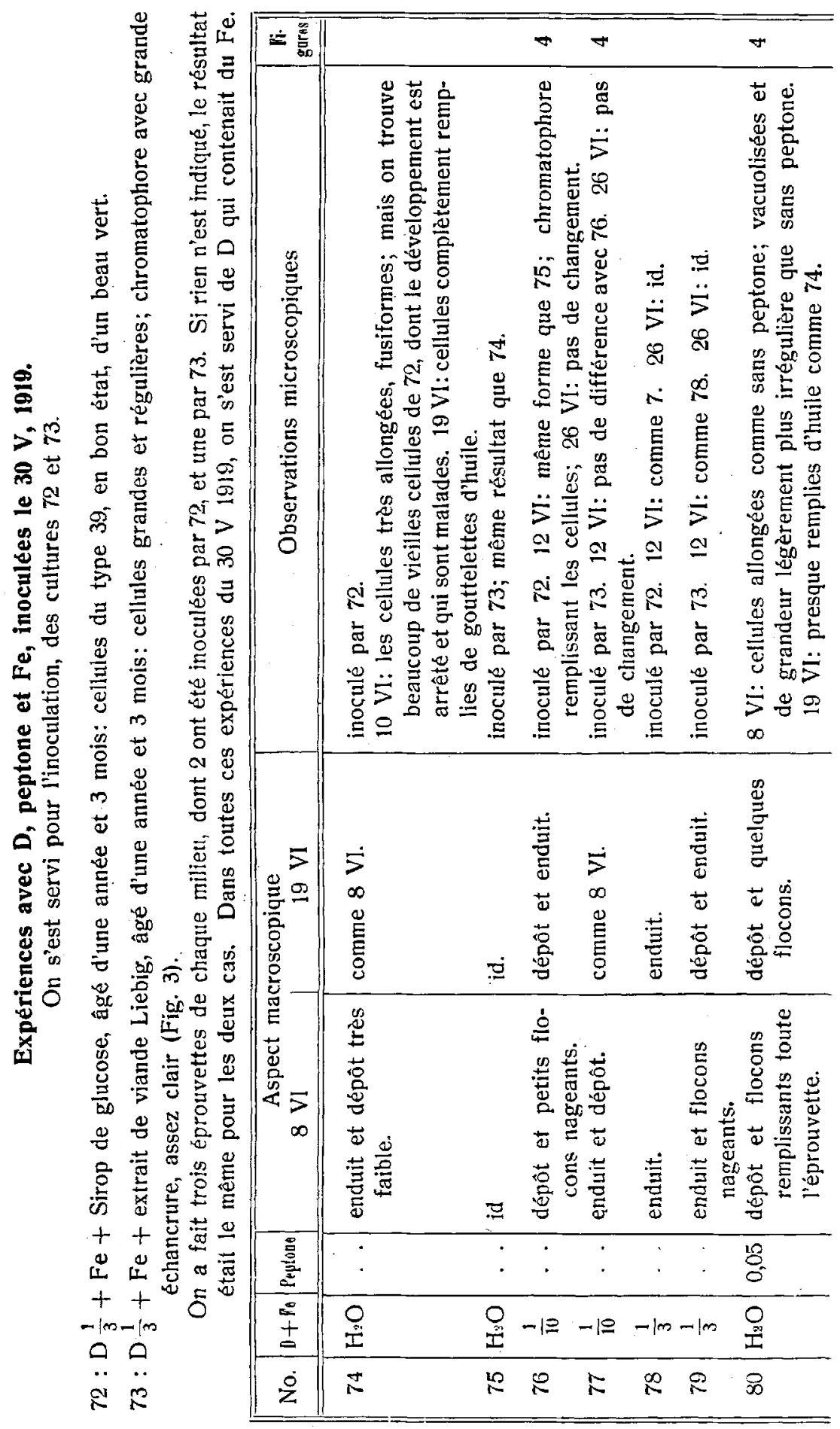




\begin{tabular}{|c|c|c|c|c|c|c|c|c|c|c|}
\hline \multirow{2}{*}{\multicolumn{4}{|c|}{ 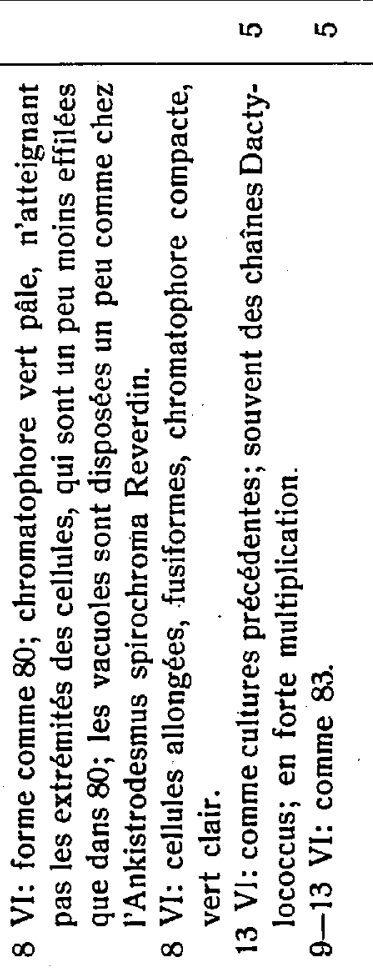 }} & \multirow[b]{2}{*}{ م0 } & \multicolumn{3}{|c|}{ m ما "m } & \multicolumn{3}{|c|}{$m$} \\
\hline & & & & & 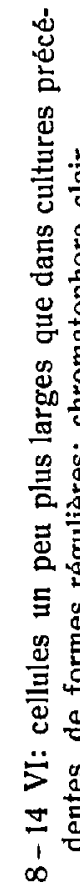 & 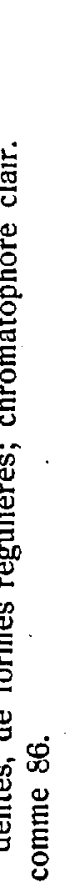 & 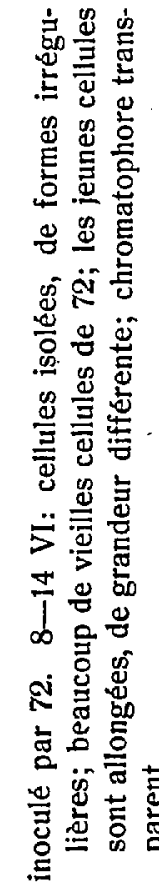 & 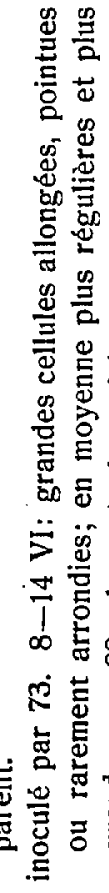 & 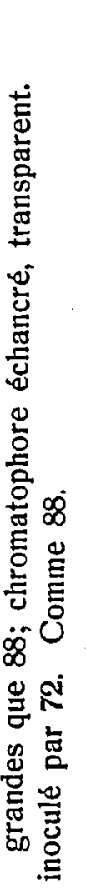 & 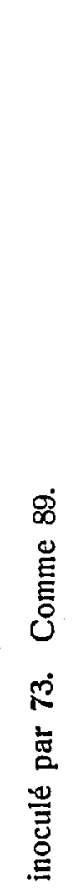 \\
\hline $\begin{array}{l}\text { 苂 } \\
\text { 号 }\end{array}$ & $\begin{array}{l}\text { 苍 } \\
\text { 总 }\end{array}$ & 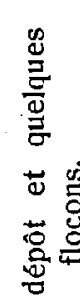 & 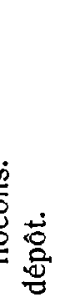 & $\begin{array}{l}\dot{0} \\
\dot{0} \\
\dot{0}\end{array}$ & 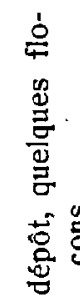 & 兽 & $\begin{array}{l}\frac{\dot{\infty}}{0} \\
\frac{D}{2} \\
. \equiv\end{array}$ & 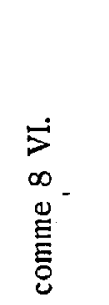 & $\begin{array}{l}\dot{P} \\
\infty \\
\stackrel{\Xi}{E} \\
\stackrel{E}{E}\end{array}$ & $\begin{array}{l}\dot{\nabla} \\
\infty \\
\dot{\Xi} \\
\text { E } \\
\dot{0}\end{array}$ \\
\hline 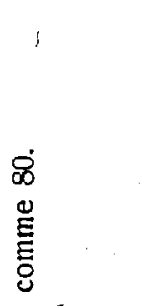 & 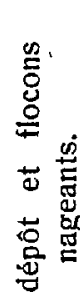 & 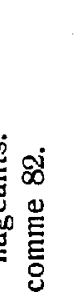 & 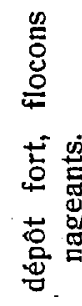 & 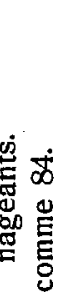 & 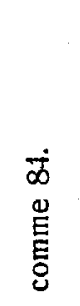 & 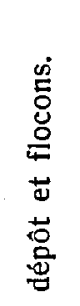 & 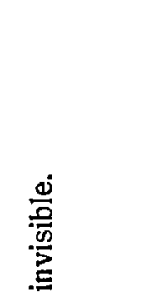 & 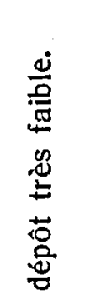 & 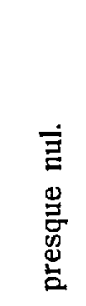 & 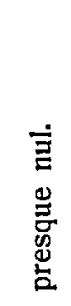 \\
\hline$\vec{\sigma}$ & 용. & $\stackrel{10}{0}$ & $\overline{0}$ & $\bar{\sigma}$ & $\underset{\sigma}{\sigma}$ & $\stackrel{\underline{\sigma}}{\sigma}$ & $\stackrel{20}{0}$ & $\stackrel{20}{0}$ & $\stackrel{10}{0}$ & 8 \\
\hline $\begin{array}{l}\text { O } \\
\text { I }\end{array}$ & -19 & -10 & -19 & $-\ln$ & -19 & -10 & -10 & -10 & $-\ln$ & -100 \\
\hline$\infty$ & $\infty$ & $\infty$ & $\bar{\infty}$ & $\infty$ & $\$$ & $\infty$ & $\infty$ & $\mathscr{\infty}$ & 8, & $\bar{\sigma}$ \\
\hline
\end{tabular}




\begin{tabular}{|c|c|c|c|c|c|c|c|}
\hline ב. & $m_{1}=$ & $m \quad m=m$ & \multirow{2}{*}{\multicolumn{2}{|c|}{ 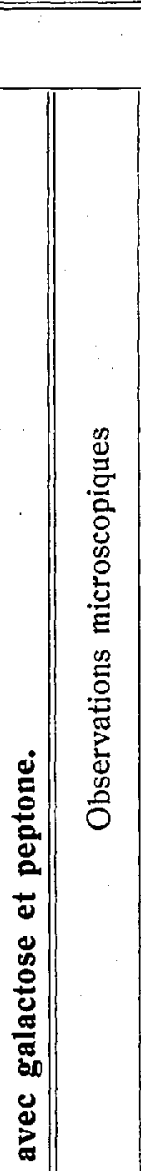 }} & $\infty$ & & $=\stackrel{\hat{m}}{\bar{p}}=m$ \\
\hline 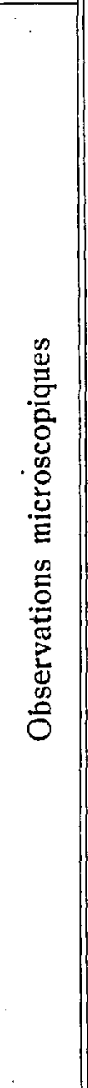 & 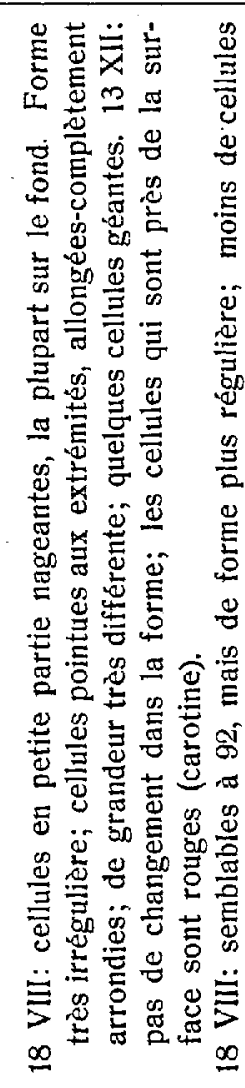 & 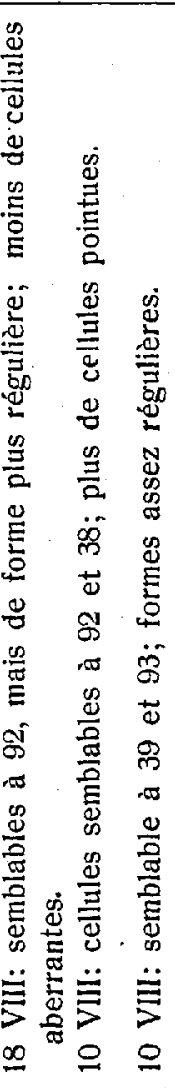 & & & 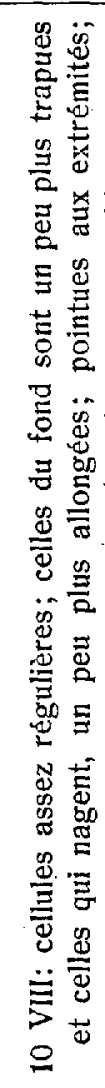 & 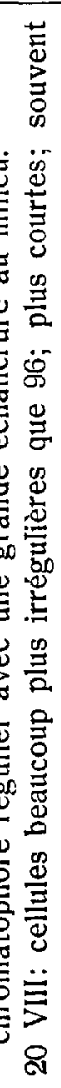 & 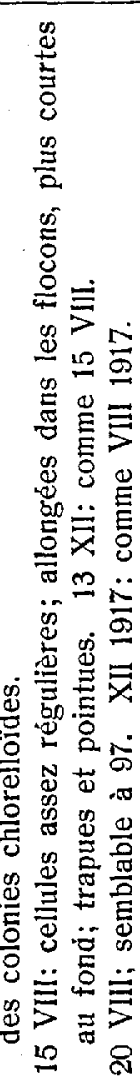 \\
\hline 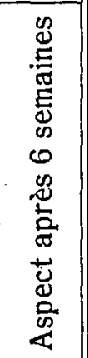 & 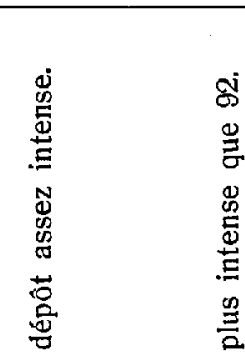 & 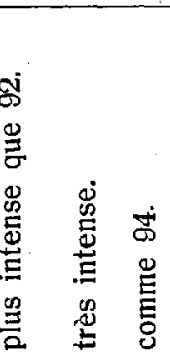 & $\widehat{a}$ & 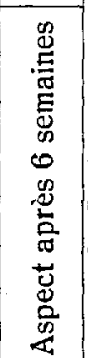 & 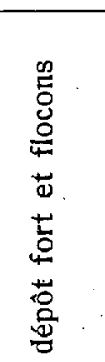 & 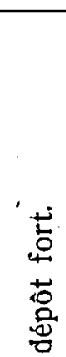 & 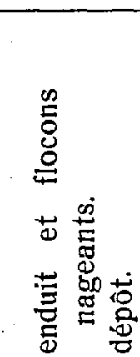 \\
\hline 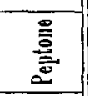 & $\stackrel{\text { g }}{o}$ & 영 뭉 영 & & $\frac{0}{2}$ & 몽 & gy & 80 \\
\hline 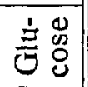 & $z \mid \nsubseteq$ & 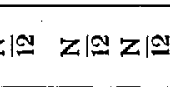 & & 产范 & $z \mid \nsubseteq$ & 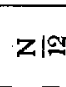 & $z|=z|$ \\
\hline $\begin{array}{l}2 \\
\pm \\
\end{array}$ & $-\mid \underline{E}$ & $100-1 \Omega-100$ & & $\stackrel{9}{ \pm}$ & -10 & $-1 m$ & $-1 \Omega-m$ \\
\hline$\dot{z}$ & Sั & $\begin{array}{lll}8 & 8 & 8\end{array}$ & & $\dot{z}$ & $\mathscr{8}$ & ธి & $\stackrel{8}{\circ} 8$ \\
\hline
\end{tabular}


dernière molécule est dissociée. Mais comme nous avons toujours affaire avec des séries de concentrations, les résultats sont quand-même de même signification. Nous avons fait, pour chaque milieu, 3 éprouvettes avec ro $\mathrm{cm}^{3}$ de liquide; les \% ont été calculés sur le volume total de la solution et pas sur le dissolvant. Toutes les cultures, inoculées d'une manière uniforme, étaient suspendues contre une fenêtre du nord, qui était protégée contre les rayons directs du soleil. Dans les tableaux qui précèdent, nous avons indiqué la concentration de la solution' nutritive en fraction de Detmer $\frac{1}{1}$, celle du $\mathrm{NaCl}$ et des sucres en fractions de solution normale, celle de la peptone en $\%$, et celle du $\mathrm{Fe}^{2} \mathrm{Cl}^{6}$ et du $\mathrm{MuSO}^{4}$ en $\frac{1}{10} \%$

\section{Discussion des expériences.}

1. Influence de la concentration de la solution nutritive. (NO I -8, 74-79) Dans l'eau pure et dans une solution D sans addition, l'Ankistrodesmus Braunii est toujours fusiforme. Dans l'eau pure, le chromatophore est très réduit, irrégulièrement échancré, clair. La cellule est transparente (Fig. 1, 1, 3; 4, 4, 8, 6; Pl. I, 1), remplie de vacuoles et contient de petites goutelettes d'huile; sa structure, par l'arrangement des vacuoles, montre une certaine analogie avec celle $\mathrm{du}$ Rhaphidium (Ankistrodesmus) spirochroma Reverdin 25 , espèce planctonique du Lac Léman. Chodat ${ }^{26}$ indique que les cellules du Rhaphidium (Ankistrodesmus) fasciculatum var. turforsum sont d'un vert bleuâtre et comme striées transversalement. Ceci provient peut-être aussi de la disposition des vacuoles. A partir d'une certaine concentration de matières nutritives, le chromatophore devient d'un beau vert et remplit la cellule, qui, alors, ne contient pas de vacuoles visibles. Dans les cultures âgées de plusieurs mois, les cellules peuvent se remplir de gouttelettes d'huiles et prendre une couleur rougeâtre (carotine). Cet état s'est produit trés rapidement dans 74 et 75. Ceci peut provenir du fait qu'on a employé pour l'inoculation un matériel provenant d'un milieu glucosé ou peptonisé

\footnotetext{
${ }^{25}$ Reverdin, 49 (1917).

${ }^{28}$ Chodat, 199 (1902).
} 

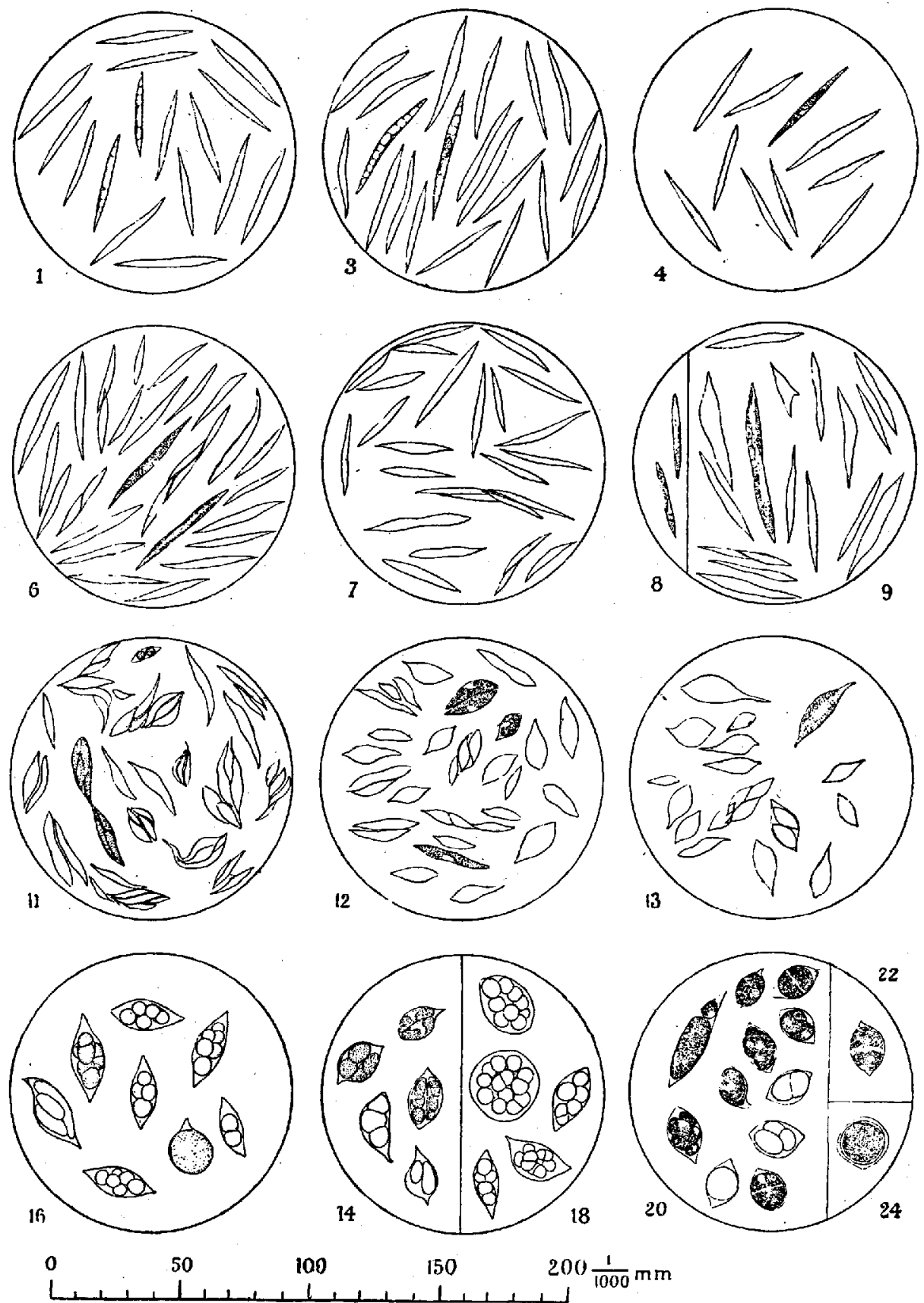

Fig. 1.

Fig. 1-3. Tous les dessins des fig. 1-3 sont faits à la même échelle. Les chiffres correspondent aux numéros des cultures dans la table des expériences. 
et que l'algue, transportée dans un milieu plus pauvre en nour. riture, a plus vite cessé de se multiplier que dans $\mathbf{I}-9$, où le matériel de départ provenait d'une culture $D \frac{1}{3}$. L'arrêt subit du développement et l'accumulation rapide de matières de réserve (en 74 et 75 ) peut aussi être la conséquence du temps splendide et chaud qui régnait pendant la durée de l'expérience. Probablement, les deux causes, disposition du matériel de jépart et questions de lumière et de température, ont agi dans le même sens pour amener la différence entre les résultats des expériences $\mathrm{I} \rightarrow 9$ et $74-75$.

2. Influence du $\mathrm{NaCl}$ (Expériences 9-30). En quantité très faible, le $\mathrm{NaCl}$ semble (à $\frac{\mathrm{N}}{60}$ ) avoir une influence stimulatrice sur le développement (exp. 9-13). Les cellules sont d'autant plus trapues que la concentration augmente. En concentration plus forte, à partir de $\frac{\mathrm{N}}{30}$, le $\mathrm{NaCl}$ ralentit, et finalement, empêche $\left(\frac{\mathbf{a}}{60}\right)$. le développement; il semble avoir une influence toxique, puisque le glucose, même en concentration plus forte, n'arrête pas encore le développement. Le $\mathrm{NaCl}$ semble favoriser la formation de spores rondes. Dans les faibles concentrations $\left(\frac{N}{60}\right)$, on peut rencontrer des cellules fusiformes dont le contenu s'est contracté pour former I ou 2 spores rondes, qui restent souvent entourées par la parois incolore de la cellule mère (Fig. 1,$11 ; 5,1$ ). A une certaine concentration (Fig. 1, 14-18, 4, 12'-13), toutes les cellules sont transformées en sporanges (à $\left.\frac{N}{12}\right)$, dont les spores continuent à se multiplier à l'intérieur lde leurs cellules mères, mais ne sont pas libérées. Si la concentration est encore augmentée, la division, elle aussi, est arrêtée et chaque cellule (à $\frac{N}{6}$ et $\frac{N}{3}$ ) qui a pris la forme d'un citron, ne contient alors qu'une seule spore (Fig. 1, 22-24).

3. Influence du glucose (expériences 31-55). Le glucose est facilement assimilable par les algues qui ont été étudiées à ce point de vue. Il ajoute donc à sa capacité osmotique des propriétés nutritives. En faible concentration de glucose, les cellules sont un peu plus grandes et plus larges que sans glucose et se développent très vite. Avec la concentration croissante, la forme des cellules devient de plus en plus arrondie et le polymorphisme plus prononcé. Une différence très caractéristique, à peine indiquée avec $\mathrm{NaCl}$, se manifeste entre le $D \frac{1}{10}$ et $D \frac{1}{3}$. Dans $D \frac{1}{10}$ l'effet du glucose se fait sentir d'une 

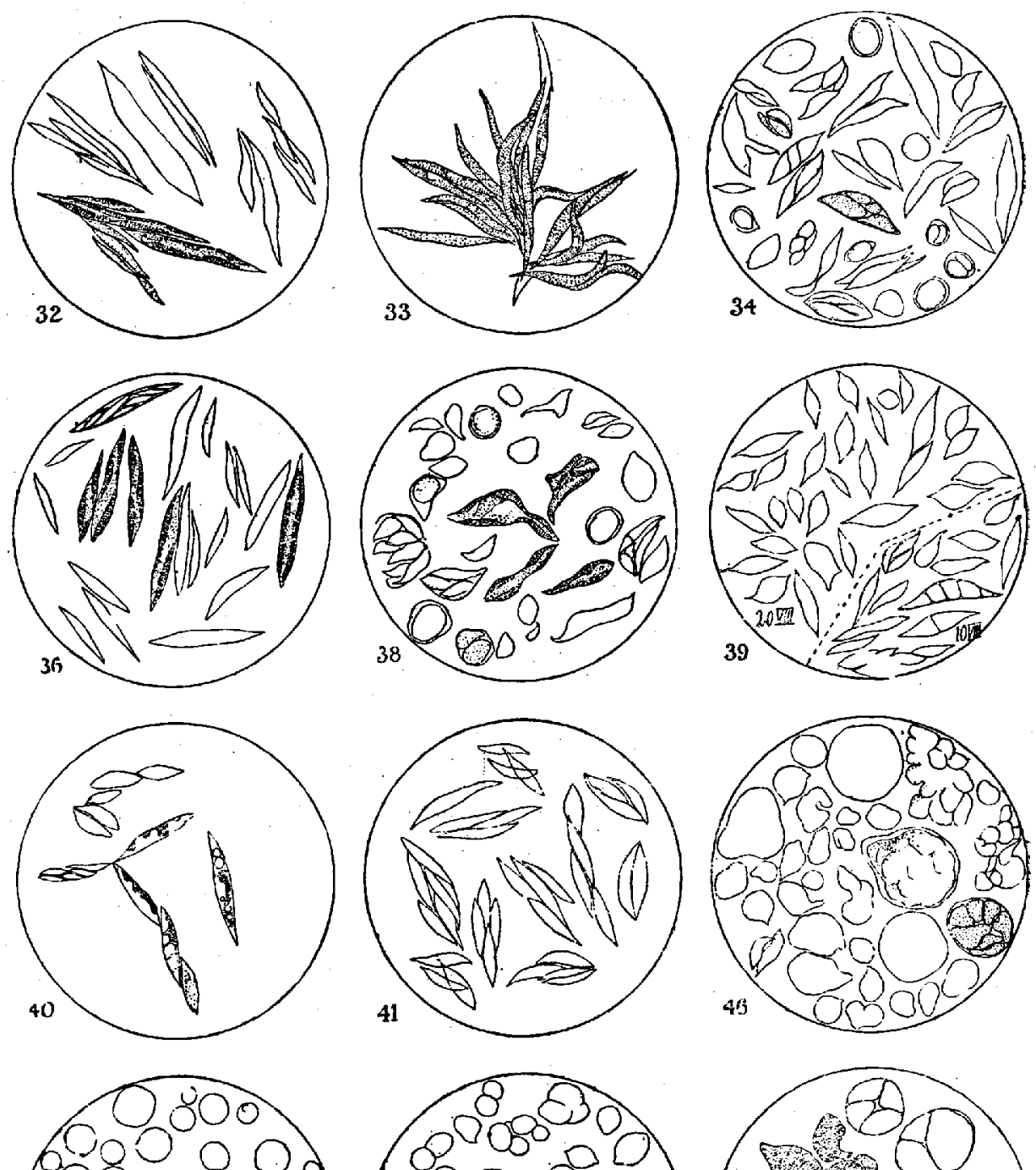

608000 od $\left(\begin{array}{ccc}000 & 00 \\ 000 & 0 \\ 0 & 09\end{array}\right)$ ${ }_{48}^{0} 00 \%$
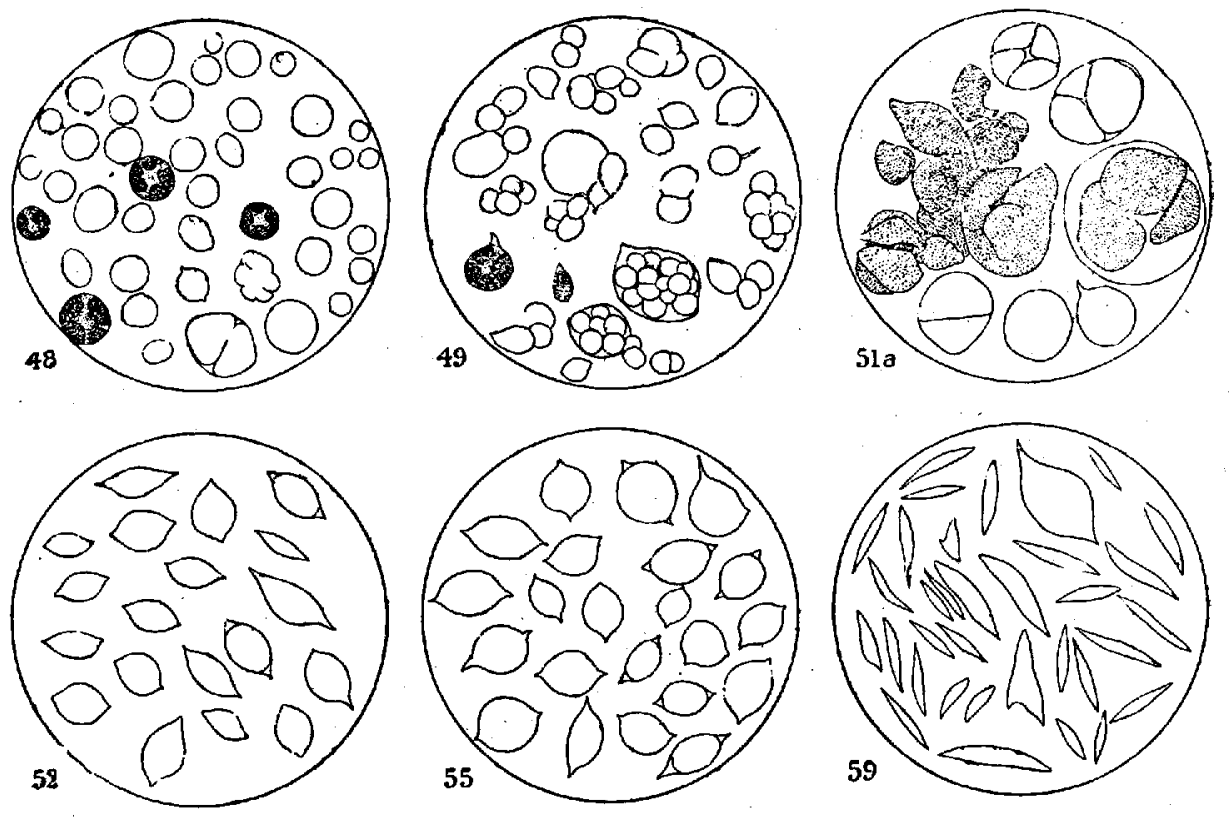

Fig. 2. 

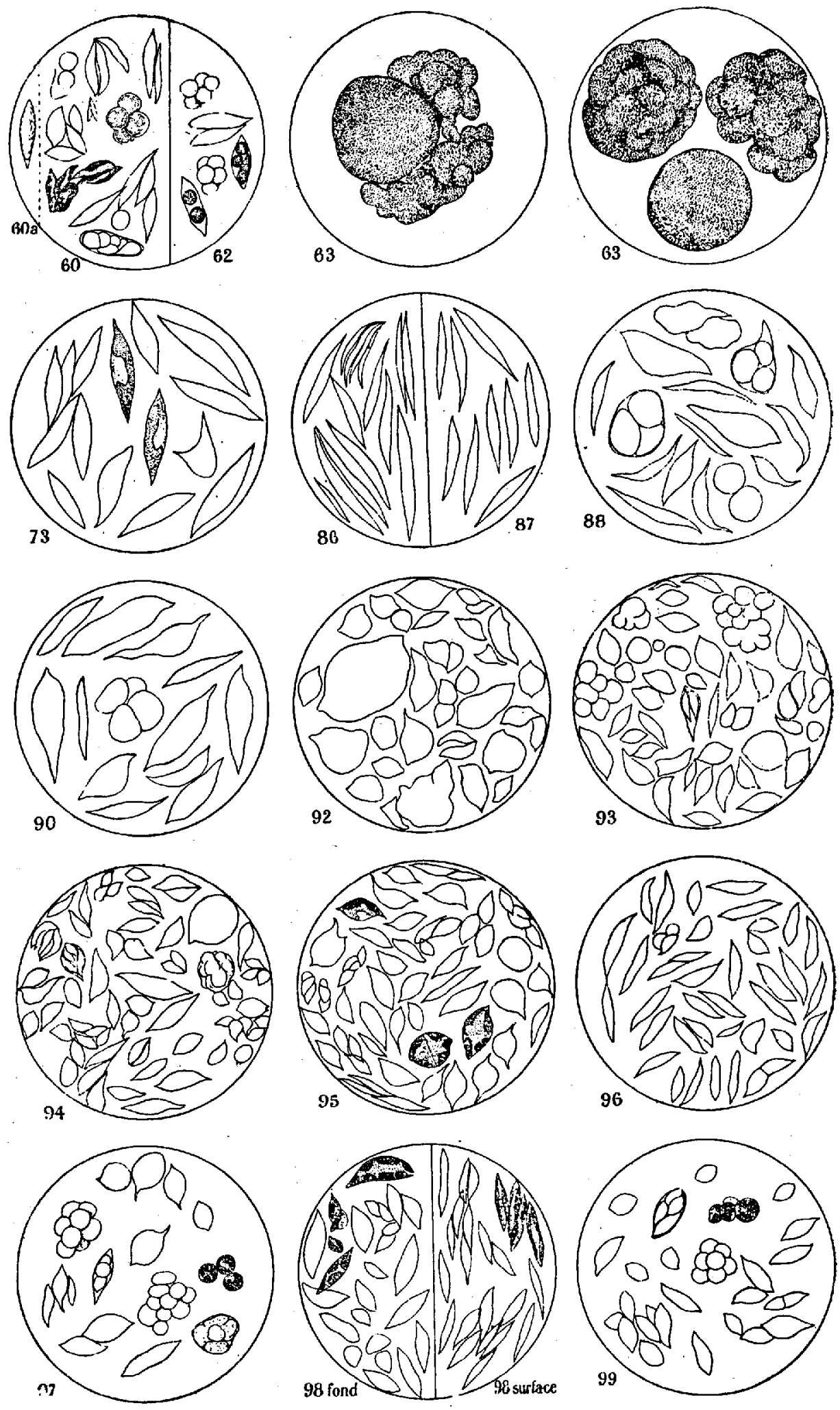

Fig. 3. 
manière plus désordonnée. Il semble que l'équilibre entre l'assimilation du carbone et la nutrition minérale, est rompu au dépens de cette dernière. Probablement, c'est surtout le noyau qui n'est pas suffisamment nourri en comparaison du reste de la cellule; la division se fait mal, la forme devient irrégulière; on rencontre des individus aberrants, et le polymorphisme est excessif. Qu'on compare sur la figure 2 le numéro 32 à 33 , 34 à 36,38 à 39,46 à 48 . Il y a probablement une substance qui est assimilée trop lentement pour pouvoir suivre l'assimilation excessive du carbone; nous sommes en présence d'un bel exemple de la loi du minimum. Aussi pouvons nous constater une dégénération plus rapide que sans glucose. Dans les solutions $\mathrm{D} \frac{1}{3}$ au contraire, la forme des cellules est plus régulière; leur croissance et leur multiplication sont coordonnées; il y a probablement équilibre entre les différentes matières nutritives et, par conséquent, le polymorphisme, dans un milieu donné, est plus faible. Aussi la dégénération semble se manifester moins vite. A une certaine concentration de glucose $\left(\frac{N}{3}\right)$, le manque d'équilibre atteint son maximum. Les cultures 50 et $5 \mathrm{I}$ ne se sont pas développées, et 5 I a ne possédait qu'un enduit très faible; toutes les cellules sont géantes et aberrantes, mais d'un beau vert. Il est à supposer, que ces grandes cellules sont plurinucléaires et que c'est le cloisonnement qui est empêché ou se fait d'une manière désordonnée. On n'a qu'à comparer fig. 2,

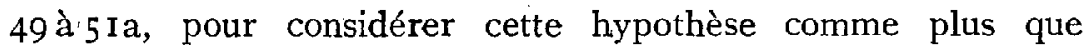
probable. Nous rappelons à ce propos que chez le Pediastrum Boryanum ( $\mathrm{Turp.}$ ) Menegh.,27 les cellules sont souvent plurinucléaires et que leur protoplaste ne se divise que très tardivement.

On aurait pu attendre, a priori, qu'en augmentant toujours la concentration du glucose, on obtiendrait des formes de plus en plus arrondies ou aberrantes. Tel n'est pas le cas. Au contraire, lorsqu'une fois une certaine concentration critique est dépassée. la forme des cellules devient de nouveau plus' régulière (forme de citron); les pointes aux extrémités réapparaissent et le polymorphisme diminue. Il est probable que, dans ces concentrations, les noyaux ne se sont plus multipliés et que

${ }^{27}$ Chodat et Huber, 11 (1895). Smith, 476, fig. 4 (1916 II). 
nous avons des cellules uninucléaires. Ces formes ressemblent beaucoup à celles qu'on observe dans les solutions de $\mathrm{Na}$ 'Cl. Mais, pour obtenir le même effet sur la forme extérieure de l'algue, il faut une concentration de $\frac{\mathrm{N}}{6}$ de $\mathrm{NaCl}$ (cult. 20 et 22). et de $\frac{\mathrm{N}}{2}$ de Glucose (cult. 52 et 53 ). La différence entre ces deux concentrations est trop forte pour être expliquée par la différence des coëfficients isotoniques (3, pour $\mathrm{NaCl} ; 2$, pour Glucose). Elle doit donc être attribuée aux différences chimiques des deux corps.

Il y a lieu de supposer que la forme arrondie n'est pas simplement l'effet de la concentration et de la pression osmotique du milieu, mais qu'elle dépend, au contraire, de l'état nutritif de l'algue. A une certaine concentration, l'effet nutritif du glucose atteint son maximum, et les cellules sont complètement arrondies; à une concentration plus forte, la disproportion entre les différentes matières devient plus grande, et le développement est mal coordonné ou tout à fait impossible (50-5 $\mathrm{ra}$ ). Si on augmente encore la concentration du glucose, la pression osmotique du milieu s'accroît naturellement dans la même proportion; mais la vitesse de l'échange des matières et de l'assimilation semble diminuer. Le développement de l'algue se fait très lentement, la division du noyau est probablement arrêtée, l'équilibre semble rétabli et la forme devient de nouveau plus régulière. La tendance à former des cellules rondes n'augmente donc pas parallèlement avec la concentration du glucose, mais subit une diminution à un certain point. Des résultats analogues ont été obtenus par Is sat $\mathrm{s} c \mathrm{~h}$ en ko.28 D'après les recherches de cet auteur, le Stichococcus bacillaris, en solution très concentrée de saccharose $(30-40 \%)$, avait les extrémités des cellules très allongées et enroulées en spirale. Grintzesco ${ }^{29}$ a déjà observé l'effet nocif du glucose, qui, chez le Scenedesmus acutus, se manifeste par une dégénération assez rapide. $\mathrm{Nak}$ a no, qui a soigneusement étudié l'influence du glucose sur le Chlorella vulgaris $\mathrm{B}$ e i j e rin ck var. lutescens $\mathrm{Nakano}$, a observé le fait suivant: ${ }^{30}$ Dans une concentration de $0,5 \%$ de glucose, l'algue utilise une quantité de glucose qui

\footnotetext{
28 Issatschenko, 11 (1911).

29 Grintzesco, 260 (1902).

${ }^{30}$ Nakano, 162 (1917).
} 
est proportionnellement plus grande que dans une concentration de $I, 0 \%$. En outre, pour une même quantité de glucose disparue, le poids sec, produit par l'algue, est plus grand dans une concentration de $0,5 \%$ que dans $\mathrm{I}, \mathrm{O} \%$.

\begin{tabular}{|c|c|c|c|c|c|}
\hline $\begin{array}{l}\text { Durée de } \\
\text { la culture }\end{array}$ & $\begin{array}{l}\text { poids primi- } \\
\text { tif du } \\
\text { glucose }\end{array}$ & $\begin{array}{l}\text { poids du } \\
\text { glucose } \\
\text { disparu }\end{array}$ & $\begin{array}{l}\text { poids du } \\
\text { glucose } \\
\text { inutilisé }\end{array}$ & $\begin{array}{c}\text { poids sec } \\
\text { produit } \\
\text { par } \\
\text { l'algue }\end{array}$ & $\begin{array}{l}\text { poids sec } \\
\text { sur } 1 \text { g de } \\
\text { glucose } \\
\text { disparu }\end{array}$ \\
\hline $1 \mathrm{VII}-10 \mathrm{X}$ & $0,5 \mathrm{~g}\left(0,5^{0} / 11\right)$ & & & & $0,260 \mathrm{~g}$ \\
\hline $20 v-10 X$ & $05 \mathrm{~g}(0,5 \%$ & 0.495 & $0,006 "$ & 0,145 & 0,293 " \\
\hline 11 VII-10X & $1,0 \mathrm{~g} \quad(1 \%)$ & 0832 & $0.168 \#$ & 0.118 & 0.142, \\
\hline 11 VII $-10 X$ & $20 \% \quad(2 \%)$ & 0.975 & 1.025 & 0.172 & 0,176, \\
\hline $29 X-1$ VII & $5 g\left(5^{\circ}: 0\right)$ & 1.900 & $3,100 ，$ & $0,525 n$ & 0271 \\
\hline $29 x-1$ VII & $\log 10^{\circ} / 11$ & 2.100 & $7,900^{\prime}$ & 0497 & 0,237, \\
\hline
\end{tabular}

Nakano conclut que, dans une solution de $0,5 \%\left(\frac{\mathrm{N}}{24}\right)$, à côté de l'assimilation de $\mathrm{CO}^{2}$, une oxydation complète du glucose peut avoir lieu. Ce procès produisant beaucoup d'énerg:e, une grande partie de glucose peut être utilisée comme matériel de construction. En concentration plus forte, une partie du glucose disparu serait mal oxydée; il se formerait une plus grande quantité de substances accessoires.

Si nous examinons la table reproduite de $\mathrm{Nak}$ a no, nous pouvons constater un fait assez étonnant: le poids sec, produit par I g de glucose disparu, atteint son minimum dans une concentration de I \% $\left(\frac{\mathrm{N}}{18}\right)$; il augmente de nouveau sensiblement dans $5 \%$. Nous pouvons peut-être supposer qu'en forte concentration, le glucose disparu est de nouveau mieux assimilé; la vie de l'algue devient complètement saprophyte et la quantité des matières accessoires et nuisibles diminue. Il y a un parallèlisme frappant entre ces faits et entre nos observations apropos des cultures 5I-55. Pour l'Ankistrodesmus Brannii, à une concentration de glucose de $\frac{N}{6}$ et $\frac{N}{3}$, le polymorphisme est excessif et la dégénération rapide; à une concentration de $\frac{\mathrm{N}}{2}$, la vie devient de nouveau possible, et le polymorphisme est moins marqué (comparez les fig. des cultures 46-55).

$\mathrm{Nak}$ ano a constaté, en milieu avec et sans glucose, la présence de formiates ( 1 c. c. p. 175). La quantité de ceux-ci 
n'augmente pas avec la quantité de glucose disparu. Leur formation n'est donc pas en rapport avec la décomposition du glucose, mais doit être considérée comme un procès normal de l'assimilation. En faible concentration de glucose $(0,5 \%)$, la quantité des formiates est plus grande; mais l'acide formique n'est pas mis en liberté (l. c. 177). En concentration plus forte de glucose, les formiates sont décomposés. Dès que la quantité d'acide formique libre atteint la concentration de $\frac{\mathrm{N}}{333}$. le Chlorella se décolore et meurt (1. c. I67). Nakano n'a pas pu mettre en évidence à quel processus cette décomposition est due. Mais il pense qu'il faut en chercher la cause dans la présence d'acides d'affinité plus forte, qui sont formés comme produits accessoires à partir du glucose dans les concentrations en question. Comme nous l'avons vu, en très forte concentration, ces produits diminuent de nouveau. Il est évident que la formation de ces matières peut contribuer à la dégénérescence et à la mort des algues, mais qu'elle ne peut être la cause du polymorphisme, tel que nous l'avons observé dans des cultures encore fraîches et vigoureuses.

4. Influence du Mn èt du Fe (Expériences I -8 et $37,-49$ ). Il est, comme $R$ ichter l'indique avec raison, ${ }^{31}$ difficile d'éliminer toute trace de Fe. Sans Fe (cult. 3), le chromatophore est réduit, échancré et presqu' incolore; l'assimilation est ralentie (en comparaison avec 4). Dans notre $\mathrm{D} \frac{1}{3}$, la quantité de $\mathrm{Fe}$ était probablement déjà suffisante pour permettre, pendant un certain temps, un développement aussi intense que sans $0,1 \%$ de $\mathrm{Fe}_{2} \mathrm{Cl}_{6}$. Mais après 5 mois, la masse totale, produite par la culture 7 , était visiblement plus grande que celle de la culture 6. Cette différence montre que, dans le dernier cas, le Fe jouait le rôle de la substance présente en quantité minumum; il suffisait pour le premier développement, mais faisait défaut ensuite. Il est intéressant de constater, à moins que nous soyons en présence d'un hasard tout particulier que, dans les milieux à forte dose de $\mathrm{NaCl}$, l'Ankistrodesmus s'est développé plus facilement en absence qu'en présence de $\mathrm{Fe}_{2} \mathrm{Cl}_{6}$. On peut peut-être s'imaginer que, la présence de $\mathrm{Fe}$ ayant une influence accélératrice, l'algue est moins gênée par les propriétés toxiques du

s' Richter, 10 (1911). 
$\mathrm{Na} \mathrm{Cl}$, si l'échange des matières est moins intense; le développement serait plus facilement troublé en présence qu'en absence de $\mathrm{Fe}_{2} \mathrm{Cl}_{6}$. Pour le glucose (exp. 49), nous voyons au contraire, que la forme de l'algue est moins troublée (exp. 18), si toutes les substances minérales, y compris le Fe, sont présentes en quantité suffisante.

Le manganèse ne peut remplacer le Fe. ${ }^{32} \mathrm{Il}$ a, au contraire, une action opposée sur le développement du chromatophore et sur l'assimilation (expér. 5, 8). On peut aussi s'en convaincre en ajoutant une dose de $\frac{1}{20}$ ou $\frac{1}{10} \%$ de $\mathrm{Mn} \mathrm{SO}_{4}$ aux milieux contenants déjà $\mathrm{du}$ Fe $($ (exp. $38-47)$. L'assimilation est ralentie, la formation des matières accessoires par conséquent probablement aussi; les matières nutritives sont lentement épuisées et le développement peut se continuer pendant longtemps; la dégénération semble se manifester moins vite (comparez expér. 38 et 39 aux suivantes). Il serait intéressant de faire des' expériences en combinant soigneusement les concentrations de $\mathrm{Mn}, \mathrm{Fe}$ et Glucose.

5. Influence du galactose (expér. 56-62). En très petite quantité, le galactose a un effet analogue à celui du glucose; mais déjà à une concentration de $\frac{\mathrm{N}}{12}(0,5 \%)$, il arrête tout développement. Nous avons d'abord pensé qu'il s'agit là d'une faute commise pendant l'inoculation (emploi de pipettes trop chaudes); mais nous avons finalement trouvé, dans une partie des cultures, quelques individus malades, et nous avons répété l'éxpérience avec le même résultat. L'effet nocif du galactose est beaucoup plus intense que celui du $\mathrm{Na} \mathrm{Cl}$; mais il peut être compensé, jusqu'à un certain point, par l'addition de peptone (exp. 96-99). Il est possible que le galactose soit attaqué par l'algue, mais qu'il se forme une grande quantité de matières inutilisables et nuisibles. Il serait fort intéressant de constater quelles sont ces substances; peut-être quelquesunes entre elles (acide lactique?) se montreraient plus toxiques pour notre algue que l'acide formique; ou bien, elles pourraient agir indirectement, en mettant de l'acide formique en liberté.

6. Influence du saccharose (expér. 63). Dans nos deux séries d'expériences avec saccharose, la plupart des éprouvettes

Richter, $19-20$ (1911'. 
étaient infectées par des bactéries, probabement à cause de la pasteurisation insuffisante. Le $\mathrm{N}^{0} 63$ nous semblait pur, mais nous n'en avons pas la certitude absolue et nous ne pouvons pas comparer son résultat avec celui des cultures dans d'autres concentrations de saccharose. Il ne nous intéresse donc qu'au point de vue purement morphologique. Il montre qu'avec les conditions réalisées dans nos autres expériences, les possibilités du polymorphisme de l'Ankistrodesmus sont loin d'être épuisées; mais il n'est pas possible de discuter sur les causes qui ont amené la formation de ces cellules gigantesques et monstrueuses et qui, surement, sont multinucléaires.

7. Influence de la peptone. $\mathrm{C}$ hodat ${ }^{33}$ a demontré l'effet ralentissant de la peptone sur le développement de l'Ankistrodesmus Braunii et plusieures espèces voisines. Celui-ci supporte difficilement un milieu gélatinisé. Dans nos expériences, en milieu liquide, une concentration de peptone de $0,05 \%-0,2 \%$ était bien supportée; le développement s'y fait avec grande vitesse; les cellules sont un peu plus grandes et plus larges que sans peptone, le chromatophore un peu échancré et clair (cult. $86,87)$. Les individus de 73 étaient, après plus d'une année, encore en parfait état de santé. La concentration de $0,5 \%$ représente la limite qui peut être supportée. Les cultures 65 , 70 et $7 \mathrm{I}$ ont péri, tandisque dans $88-9$ I un faible développement a eu lieu. Cette différence est probablement la conséquence du fait que, pour ces dernières cultures, on a employé un matériel d'inoculation qui provenait d'un milieu glucosé ou peptonisé, tandisque pour les premières il provenait d'un milieu $\mathrm{D} \frac{1}{3}$ sans autre addition. La différence entre le milieu de départ et celui de l'expérience était donc moins grande dans les cultures 88-9I ; l'organisme était déjà un peu accoutumé et dans un état de nutrition qui le rendait plus capable de supporter la forte dose de peptone. Nous reviendrons encore sur ce point.

Si l'on combine l'effet de la peptone avec la présence de glucose, on remarque tout d'abord que la concentration de $0,5 \%$ de peptone est supportée avec grande facilité et que

${ }^{33}$ Chodat, $96(1909)$ et 131-136 (1913); Hoffmann-Grobéty, 86 (1912. 
le développement y est très intense. Chose étonnante, même le galactose à $\mathrm{I}, 5 \%\left(\frac{\mathrm{N}}{12}\right)$, qui était nuisible sans peptone, favorise le développement en présence d'une concentration de peptone qui, sans galactose, serait aussi nuisible. Pour l'Ankistrodesmus minutus, Chodat ${ }^{34}$ a constaté que le pouvoir de liquéfaction de la gélatine et la capacité protéolytique vont en diminuant, si l'on augmente la quantité de glucose. Mais le saccharose, qui, lui seul, est difficilement assimilé, semble l'être beaucoup mieux en présence de peptone (ibid. p. r 34); il ne diminue pas le pouvoir protéolytique de l'algue; son rôle est donc contraire à celui du glucose et reste problématique. Pour l'Ankistrodesmus Braunit, le galactose joue un rôle analogue et que nous ne pouvons nous expliquer pour le moment (expér. 96-99). On peut aussi supposer que des acides qui se forment aux dépens du galactose, sont neutralisés par des bases aminées qui se forment à partir de la peptone. Mais nous n'avons pas fait d'analyses chimiques de nos milieux. Dans les expériences avec peptone et glucose combinés, nous sommes de nouveau en présence d'un exemple de la loi du minimum. 92 et 94 , avec $\mathrm{D} \frac{1}{10}$, sont très polymorphes; 93 et 95 , avec $\mathrm{D} \frac{1}{3}$, le sont moins. Avec galactose le contraire a lieu; dans $\mathrm{D} \frac{1}{3}$, on voit le polymorphisme plus prononcé que dans $\mathrm{D} \frac{1}{10}$, ce qui est peut-être en rapport avec le rôle inconnu de ce sucre.

En somm:; le développement de l'Ankistrodesmus Braunii dans un milieu avec $1,5 \%\left(\frac{\mathrm{N}}{12}\right)$ de glucose ou de galactose, est favorisé par l'addition de peptone (comparez 38 à 92 et 94 ; $3^{19}$ à 93 et 95). On peut rapprocher à ces observations, le fait déjà cité, et confirmé par plusieurs auteurs, ${ }^{35}$ que d'autres Protococcacées attaquent moins la gélatine en présence de glucose, qu'en absence de celui-ci.

\section{Morphologie et valeur systematique des formes observées.}

Nous avons déjà énuméré les différentes formes' de l'Ankistrodesmus, qui ont été décrites jusqu'àprésent, soit dans la nature, soit en culture pure. Nous avons rencontré, dans les conditions réalisées dans nos expériences, presque toutes ces formes ou, au moins, des types analogues.

\footnotetext{
${ }^{34}$ Chodat, 135 (1913).

${ }^{35}$ Hoffmann-Grobéty, 87 (1912).
} 
Dans les cultures âgées, en faible concentration, les cellules restent allongées, se remplissent de gouttelettes d'huile et prennent la couleur rouge de la carotine. Celle-ci peut se former dans presque tous les milieux; il semble que sa production est favorisée par le glucose. Il y a donc une analogie avec la formation de ce pigment chez les plantes supérieures.

Les cellules allongées et pointues, contenant une ou deux spores arrondies (Fig. $T, 11 ; 3,62 ; 5,1$ ), se sont formées dans les milieux $\mathrm{D} \frac{1}{10}$ et. $\mathrm{D} \frac{1}{3}$ avec faible dose de $\mathrm{Na} \mathrm{Cl}$, Glucose et Galactose; nous les avons observées dans 6, 9, Io, I I, 32. Mais ces formes si typiques ne se sont produites, dans nos milieux, qu'en très petit nombre; nous n'avons pas, dans nos cultures, réalisé les conditions optima à leur formation. Le fait qu'on les trouve par-ci, par-là, entre des individus restés fusiformes, sans rencontrer des formes intermédiaires, montre que leur apparition n'est pas la conséquence d'une haute pression du milieu, mais d'un état particulier de l'individu. La présence de $\mathrm{Na} \mathrm{Cl}$ semble pourtant favoriser cette sorte de multiplication. Dans une série de cultures, infectée accidentellement par des bactéries, ces formes nous paraissaient plus nombreuses (influence des matières sécrétées?).

Dans les cultures à $\mathrm{Na} \mathrm{Cl}$ plus concentré, toutes les cellules se transforment en véritables sporanges, à parois solides. Les spores continuent leur multiplication; les produits de division restent enfermés dans la parois de leur cellule mère, et on obtient ainsi des sporanges allongés à un assez grand nombre de spores (Fig. I, 16-18; 4, 12-13). Dans les concentrations encore plus fortes, la multiplication est arrêtée, les sporanges deviennent unispores (Fig. 1, 20-24). Les cellules allongées et isolées ont la capacité de se fixer sur différents objets; elles rapellent alors un Sciadium ou un Characium. Cette capacité est particulièrement prononcée dans les cultures avec une faible dose de $\mathrm{Na} \mathrm{Cl}$, sucre ou peptone. On voit alors, à l'extrémité de la cellule, un point qui se colore en rouge par le rouge de congo et qui se fixe immédiatement sur la lame ou la lamelle. Cette fixation est si efficace, qu'on voit l'algue se tourner, sous le microscope, comme une girouette selon le courant d'eau, et qu'on peut même rincer la lamelle sous un robinet sans arracher toutes les cellules. Rappelons; à cette 


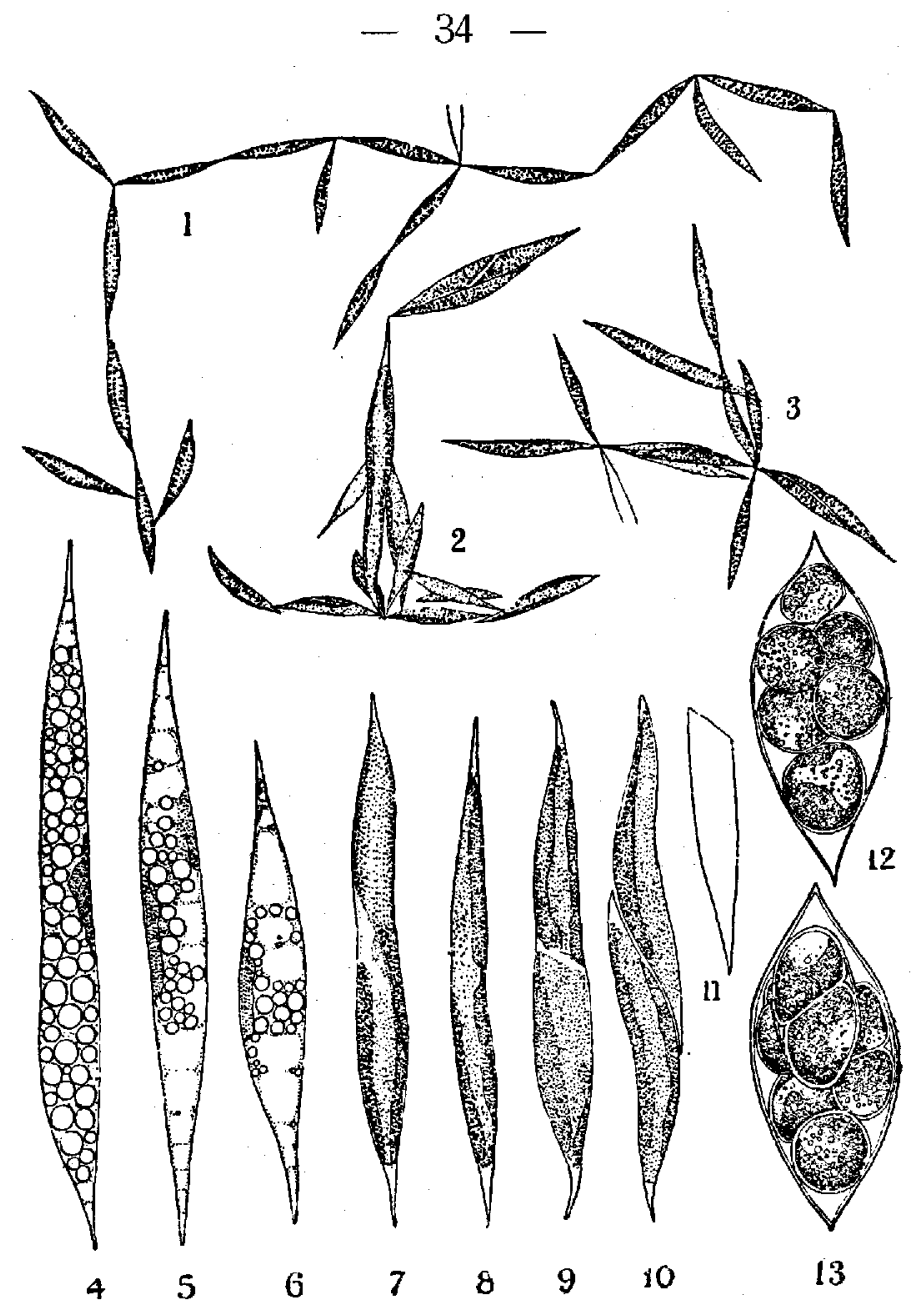

Fig. 4.

Fig. 4. 1-3 Culture 77; stade Dactylococcus (15 V, 1919); même grossissement que fig. 5 .

4-6 Culture 80; cellules vacuolisées, se remplissant d'huile (19 VI, 1919).

7-11 Culture 76; stades successifs de division; 11, reste de la parois.

$12-13$ Culture 16 ; sporanges à parois solides.

Fig. 5. 1 Culture 11; division normale et formation de spores. Les deux modes peuvent se rencontrer dans un même individu.

2-5 Culture 7; en 2, individus isolés qui se sont accrochés accidentellement; en 3 , la cellule d'entrant continuera la chaine Dactylococcus.

6-8 Culture 85; étoiles nageantes et Dactylococcus; en 6 en voie de multiplication.

9 Culture 83; flocon avec etoiles et Dactylococcus, en voie de forte multiplication.

10 Culture 87; chromatophore plus transparent.

11-13 Culture 84; agée de 8 jours; on remarque, à la base de chaque arbuscule, la parois de la cellule plus trapue qui provient de l'inoculation.

14, 15, 17 Culture 86; comme 11-13.

16 Culture 84 , agée de 14 jours; la cellule basale est plus pointue que dans 11-13; grossissement un peu plus fort. 


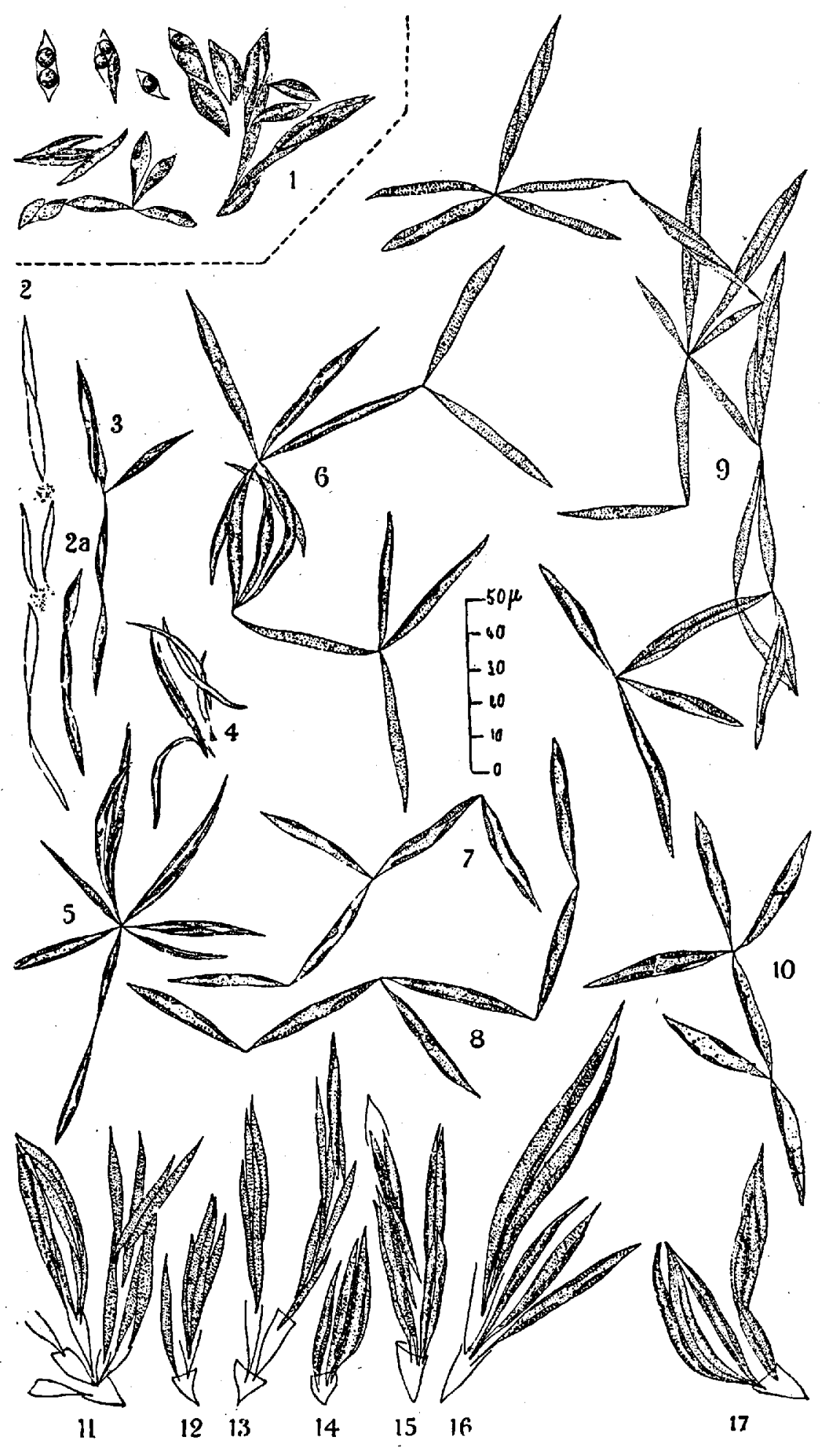

Fig. 5. 
occasion, que d'après Borge, ${ }^{36}$ le Spirogyra forme plus facilement des rhizoïdes en présence d'une certaine quantité de sucre $(0,25-0,5 \%$ de Saccharose $)$ que sans cette addition.

Les beaux arbuscules, décrits par $\mathrm{Chod}$ at pour l'Ankistrodesmus falcatus ( $\mathrm{Corda}$ ) Ralfs, n'ont plus été retrouvés depuis lors. Ce n'est que dans nos dernières expériences en I9I9, que nous avons réussi à découvrir de formes analogues. Cependant, dans les dessins de $\mathrm{Ch}$ od at, leur forme est encore plus régulière. ${ }^{37}$ Nos arbuscules n'étaient pas fixés, mais se rencontraient dans les flocons nageants. Ils se sont formés dans des cultures ( $\mathrm{N}^{0} 84,86$, fig. 5, 11-17) D $\frac{1}{10}$ et $\mathrm{D} \frac{\frac{1}{3}}{3}$ avec faible addition de peptone, donc dans des conditions où la vitesse de développement était très grande. Nous ne les avons observés que pendant les premiers temps après l'inoculation, ou l'intensité de la croissance atteignait son maximum. On trouve, à la base d'une partie de ces arbuscules, encore le reste de la vieille cellule mère plus trapue, qui provient de l'inoculation. Le temps, pendant ces expériences, était très chaud et lumineux. Nous pensons donc que nos arbuscules, qui d'ailleurs étaient très débiles, se sont produits parce que toutes les circonstances se sont accumulées pour accélérer la croissance, et que leur formation est liée à une certaine vitesse de la multiplication. Si le développement se fait lentement, nous n'avons, dans le même milieu, que des cellules isolées, issues par deux dans chaque cellule mère. Comme $\mathrm{Ch}$ odat avait observé ses arbuscules fixés sur des algues filamenteuses, nous avons introduit du coton stérilisé dans nos cultures. Les algues s'y sont fixées en assez grand nombre, mais sont restées isolées et nous n'avonis pas réussi à observer des arbuscules fixés. Probablement, nous avons introduit le coton à un moment, où la vitesse de développement (ro jours après l'inoculation) avait déjà dépassé son maximum.

La forme Dactylococcus était obtenue dans des conditions semblables (cult. $77,85,83,87$ ). On voit une cellule se diviser en deux ou plusieures cellules filles, qui restent unies par leurs extrémités. Ceci peut se répéter plusieures fois. $\mathrm{Si}$, à chaque

${ }^{36}$ Borge, 34 (1894).

${ }^{3}$ Chodat, 609 (1894) et 168, 199 (1902). 
division, le nombre des cellules filles est petit, nous obtenons (fig. 4,$4 ; 5,3,5,7,8,10$ ) de longues chaînes peu ramifiées, composées de $3-5$, très rarement de Io individus. Si chaque individu donne naissance à un nombre considérable de cellules filles, nous obtenons des systèmes d'étoiles extrêmement élégants dont on voit bien le mode de formation en fig. $4,_{2}$ et fig. $5,5,6,9$. La disposition des cellules dans ces étoiles rappelle celle chez les Actinastrum ${ }^{38}$.

On peut rencontrer ainsi des flocons nageants composés de centaines d'individus. Il est évident que certains de nos dessins (fig. 4,1 ) rappellent énormément le stade Dactylococcus chez Scenedesmus acutus ${ }^{39}$ et constituent une preuve de plus de l'affinité entre les deux genres. Il ne faut pas confondre, avec ces formations naturelles, les chaînes qu'on rencontre souvent et qui sont issues de la réunion accidentelle d'individus isolés, fixés les uns aux autres par leurs extrémités (fig. $5{ }_{2}$ ). La forme Dactylococcus, de même que les arbuscules, sont difficiles à observer. Même dans leṣ conditions qui farvorisent leur apparition, nous avions toujours de la peine à les étudier en exemplaires typiques et bien conservés. Nous insistons encore sur le point que la fréquence des formes rares est dominée par la loi des courbes de variations. Chaque milieu a son mode caractéristique. Dans certains cas, le sommet de la courbe serait très accentué et les formes extrèmes s'éloigneraient peu du mode; dans d'autres, la courbe serait plus applatie et les formes aberrantes plus nombreuses.

Les formes chlorelloïdes enfin, semblent être favorisées en milieu avec glalactose $\left(60-62 ; 97\right.$ et $99 ;$ Planche II, $\left.{ }_{10}\right)$.

\section{Le problème de la flottaison.}

Le lecteur trouvera traitée la question de la flottaison des organismes du plancton dans les travaux de $\mathrm{R}$ ayss et de Grossmann, qui contiennent aussi la bibliographie nécessaire. Nous n'avons qu'à rappeler qu'une viscosité du milieu ou une grande surface spécifique de l'organisme ralentissent la vitesse d'immersion et facilitent la flottaison. On est en droit de

8s Chodat, 208 (1902); Brunnthaler, 169 (1915).

39 Grintzesco (1902). 


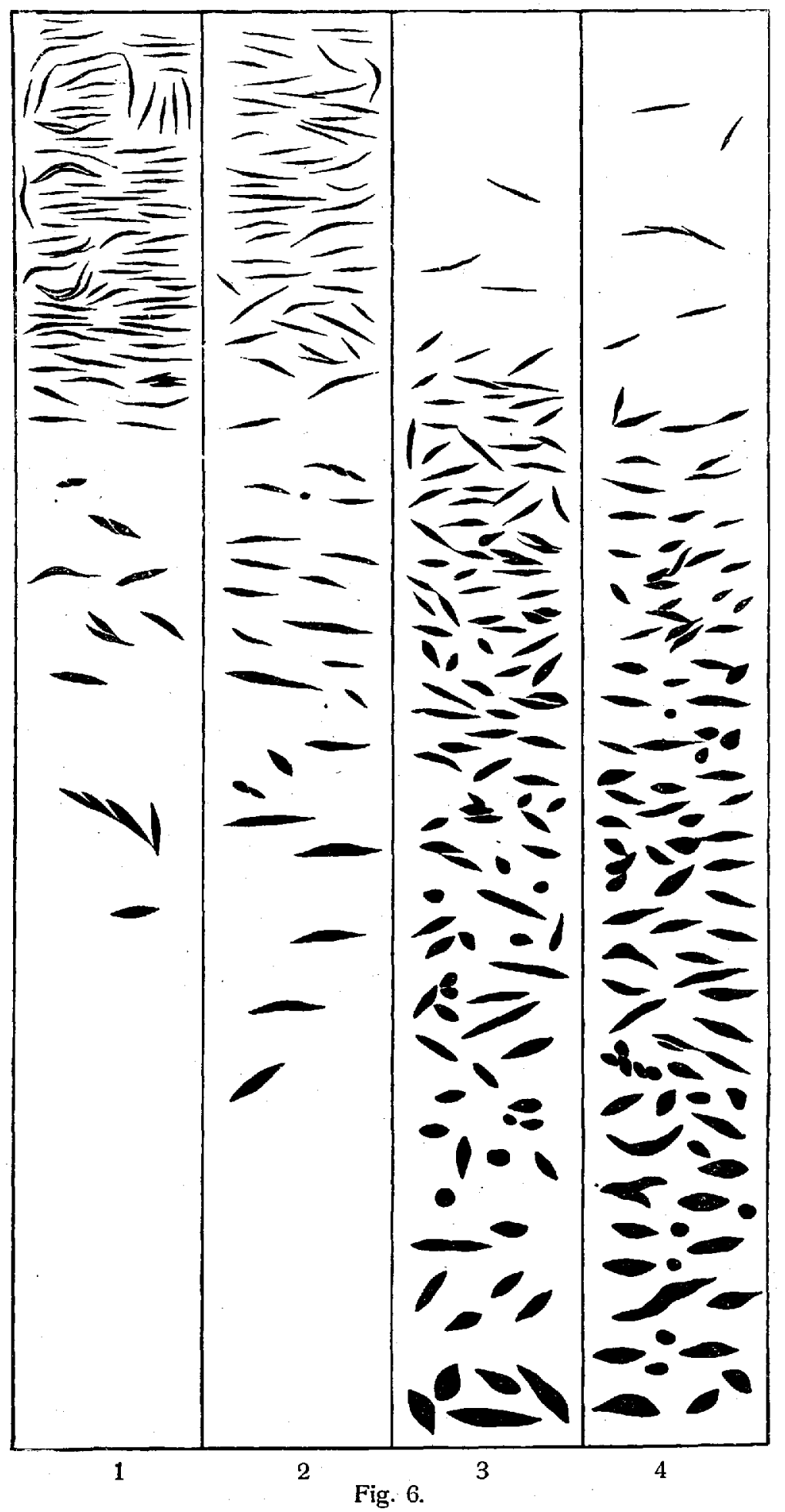

Explication dans le texte. 


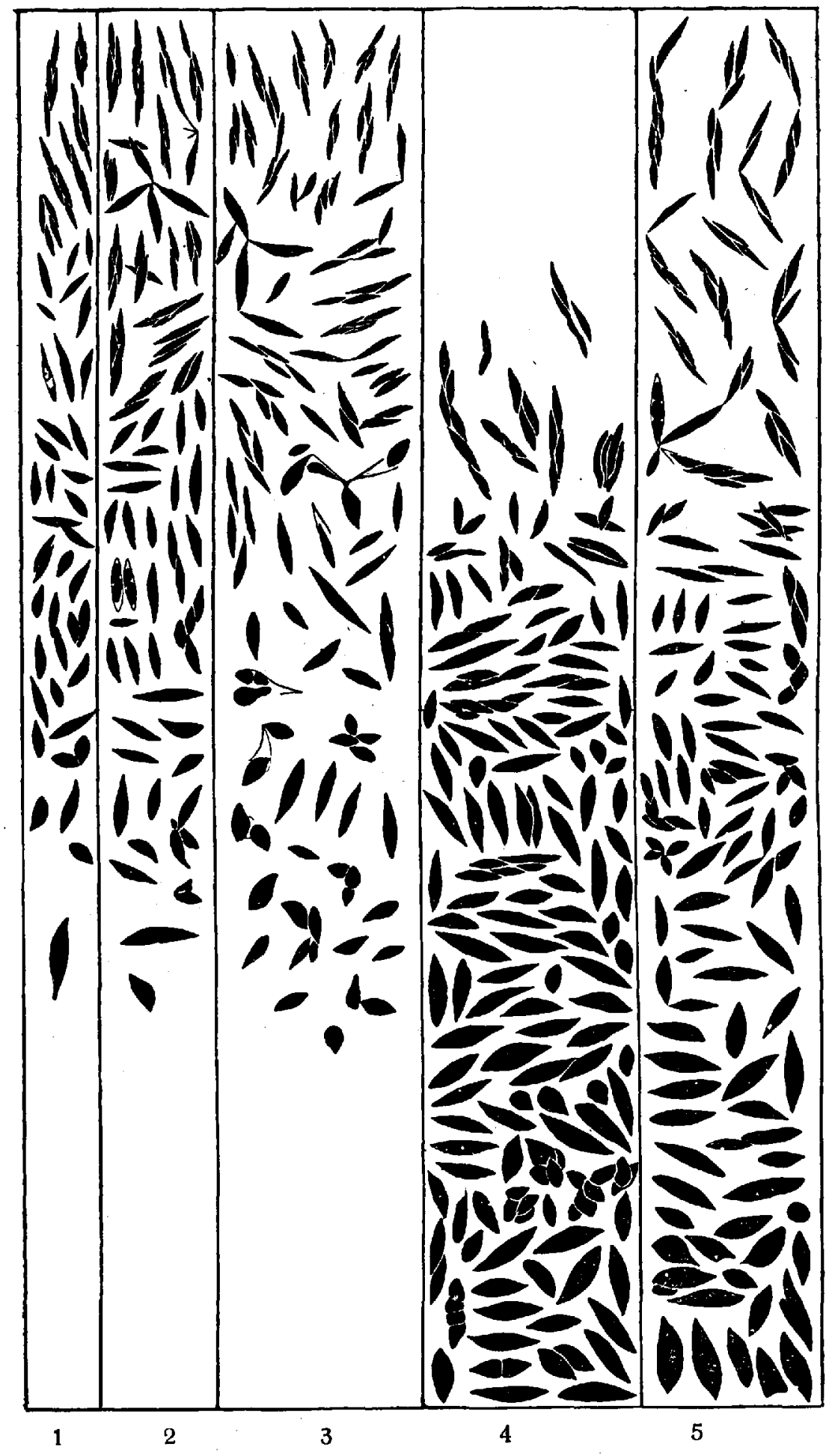

Fig. 7. 
supposer que, dans une même culture en milieu liquide, les conditions de nutrition sont à peu près les mêmes pour la plupart des individus, et qu'ils ont tous à peu près les mêmes propriétés de viscosité vis-à-vis du milieu. C'est donc surtout leur forme extérieure qui les distingue les uns des autres, et si un individu descend plus vite qu'un autre, il faut en chercher la cause dans cette différence des formes extérieures. Il semble qu'on peut étudier, dans de telles circonstances l'influence de la forme extérieure sur le pouvoir de flottaison, avec une grande netteté.40 Certaines causes d'erreur sont éliminées, celles-ci étant inévitables quand on compare deux organismes différents dans un même milieu ou un organisme dans différents milieux.

Pour l'expérience du 4 mars 1918, nous avons pris la culture 58 , inoculée le 17 VII 1917 . Avant l'expérience, l'éprouvette n'avait pas bougé pendant des mois; il y avait un dépôt au fond et le liquide était très légèrement teinté en vert par les individus nageants. Dans la colonne I (fig.6) on a dessiné un certain nombre d'individus, rencontrés au pur hasard près de la surface du liquide avant de l'avoir remué. Puis, la culture a été fortement secouée. Dans la colonne 4 , on a dessiné un certain nombre d'individus rencontrés dans une goutte prise immédiatement après; dans la colonne 3 , des individus pris au fond après 2 heures; dans la colonne 2 , des individus pris près de la surface après 2 heures $1 / 4$. On a groupé, pour mieux comparer les différentes catégories, les individus minces et allongés en haut, les gros en bas.

On constate donc, par l'emploi de cette méthode statistique, que, toutes choses étant aussi égales que possible, les gros individus trapus descendent, et les individus minces et allongés restent facilement en suspension. La différence entre les deux catégories (colonne 3 et colonne 2) est assez bien marquée dans ce milieu. On trouve cependant, dans les colonnes $I$ et 2 (individus nageants) quelques cellules assez trapues et dans la colonne 3 (individus du fond) quelques-unes qui sont minces.

Tout différent est le résultat de l'expérience 2 du 20 VIII 1917 avec la culture 98. Dans la colonne 5, on voit les in-

40 Vischer, 229 (1917). 
dividus d'une goutte prise immédiatement après avoir secoué le contenu; dans la colonne 4 , des individus du fond après 3 heures $1 / 4$; dans 3 , des individus pris près de la surface aprè 4 heures; dans 2, après 7 heures; dans I, après 21 heures. On remarque de prime abord que tous les individus sont plus trapus que dans la culture 58; tous, dans le milieu moins visqueux de l'expérience $I$, seraient tombés au fond. On voit donc l'influence de la viscosité du milieu (présence de peptone) sur le pouvoir de flottaison. Des organismes incapables de rester en suspension dans un milieu donné, peuvent flotter, si la viscosité est plus grande. Peut-être, une différence de poids spécifique s'ajoute pour agir dans le même sens. Dan's l'expérience 2 , la différence entre les individus flottants et ceux qui tombent au fond, est moins marquée que dans l'éxpérience $\mathbf{I}$. Le nombre de ceux qu'on pourrait tout aussi bien trouver dans la colonne 3 que dans 4 , est assez grand. Mais, sur la quantité totale, le nombre des petites cellules, souvent réunies par quatre ou en forme d'étoile, est plus grand dans la catégorie des individus nageants (colonne $\mathrm{I}-3$ ) que dans la catégorie de ceux qui tombent au fond.

Chez ces derniers (colonne 4), le nombre des grands l'emporte de beaucoup. Nous donnons (Pl. II, 5) la photographie d'un flocon nageant, qui était pris avant d'avoir secoué l'éprouvette; ces colonies sont très débiles. On remarque aussi, en comparant la colonne I à 3 , que les individus qui sont restés en suspension après 4 heures, le sont encore après $2 \mathrm{I}$ heures. Dans fig. 6, colonne I, on voit ceux qui flottent depuis des mois. Il faudrait naturellement augmenter ces expériences en faisant plonger par exemple, dans des m:lieux différents, des individus provenants du même milieu. On aurait alors la certitude, que les différences dans la vitesse d'immersion doivent être attribuées à l'influence du milieu (viscosité, poids spécifique, température); on pourrait exclure d'une telle manière les causes d'erreurs qui proviennent de l'état différent du matériel employé (état de nutrition, poids spécifique, viscosité, gelée etc.). On pourrait aussi faire des essais complémentaires, en transportant du matériel de provenance différente, dans un même milieu donné, pour étudier l'influence de l'état de nutrition etc: sur le pouvoir de flottaison. 
Le pouvoir de flottaison. s'est manifesté d'une façon très ditférente dans les cultures 74-87. Comme l'indique le tableau des expériences, on a observé, pendant les premiers temps après l'inoculation, un développement très intense de flocons nageants (arbuscules, Dactylococcus etc.). Ces flocons étaient surtout abondants en présence d'une petite dose de peptone. On ne pouvait, sous le microscope, constater aucune différence entre les individus nageants, et ceux du fond. Après un certain temps ( $2-3$ semaines), presque tous ces flocons nageants avaient disparu, et il n'en restait qu'un faible enduit sur la parois de l'éprouvette opposée à la lumière. Les algues n'étaient donc capables de monter vers la surface et de rester en suspension que pendant la période où l'intensité de développement atteignait son maximum. Dès que la vitesse de l'assimilation et de la croissance allait en diminuant, tous les individus tombaient au fond. Le pouvoir de flottaison était donc lié, dans ce cas, à un stade particulier de nutrition qui ne durait que pendant une quinzaine de jours. Ce phénomène peut être rapproché du fait bien connu, que beaucoup d'organismes du plancton n'ont été observés que pendant une période țrès restreinte. Il est intéressant de constater, que la présence d'innombrables gouttelettes d'huile, n'a pas empêché les cellules des cultures 74 et 75 , de tomber au fond et d'y rester.

\section{Rapport entre les conditions physico-chimiques et les formes produites.}

Si nous nous demandons, quels sont les rapports physicochimiques entre les milieux et les formes produites, nous devons avouer que nous n'en voyons point. La forme ronde (culture 48) qui, de prime abord, pourrait être considérée comme une réponse directe à la pression osmotique du milieu, ne l'est pas; elle ne se forme plus, si la concentration est encore augmentée. L'apparition des cellules en forme de citron, dans les hautes concentrations de glucose, n'a pas plus de rapports physicochimiques avec le milieu, que celle des cellules allongées et spiralées du Stichococcus bacillaris ${ }^{41}$ dans les hautes concentrations de saccharose. Nous ne pouvons non plus nous expliquer,

41 Issatschenko, 11 (1911). 
chez l'Ankistrodesmus Braunii, la formation d'un pied fixateur dans les milieux avec faible dose de sucre ou de $\mathrm{Na} \mathrm{Cl}$. De même, la formation des chaines Dactylococcus chez les Scenedesmus et chez les Ankistrodesmus, et celle des arbuscules, reste inexplicable par des raisons physico-chimiques. Nous ne pouvons pas, non plus, constater le moindre rapport entre l'utilité que pourrait avoir une forme (augmentation de surface en milieu pauvre etc.), et les conditions qui la provoquent. Il se peut que, par hasard, une forme soit utile; mais ce n'est pas nécessairement le cas. On n'est donc pas en droit de parler, dans les cas décrits, de réactions ,adéquates". La production de gouttelettes d'huile, dans les expériences 74 et 75 , n'a pas servi à faciliter la flottaison, ma:s est simplement la conséquence d'un certain état de nutrition. Nous ne pouvons que répéter ce que nous avons dit à propos de la formation des hélicomorphoses (feuilles juvéniles) chez les plantes supérieures: ${ }^{42}$ "Irgend eine Beziehung zu einem Bedürfnis der Pflanze kommt hiebei nicht in Betracht.“ „Die Pflanze kann in keinem Fall das tun, was für sie von Vorteil wäre, sondern das, wozu sie gezwungen wird."

Le mode de réaction de l'algue vis-à-vis du milieu est donc uniquement déterminé par les facteurs héréditaires. Aux différentes conditions, l'algue doit répondre par la formation d'une certaine morphose selon ces lois. La forme de la morphose n'a aucun rapport direct, utilitaire ou physico-chimique, avec les conditions dans lesquelles elle est produite.

\section{Influence de l'état du matériel d'inoculation sur le résultat des expériences.}

Nous avons déjà attiré l'attention sur le fait, qu'en répétant une expérience, même à partir de cultures pures, on n'obtient pas toujours exactement le même résultat. Pour le Chlorella vulgaris, $\mathrm{N}$ a ka n ${ }^{43}$ a observé que les résultats des expériences (surtout la vitesse de développement), dépendaient, jusqu'à un certa:n point, de l'âge du matériel de départ. Nous avons nous-même pu constater qu'une quantité de peptone de $0,5 \%$ était mieux supportée, si le matériel d'inoculation provenait

- ${ }^{23}$ Vischer, Experimentelle Beiträge zur Kenntnis der Jugend- und Folgeformen; Flora, neue Folge, vol. VIII, 59 (1915.

4. Nakano, 16 (1917). 
dejà d'une culture avec glucose ou peptone. Dans de l'eau ou dans $\mathrm{D} \frac{1}{10}$, les algues provenant d'un milieu minéral $\left(\mathrm{D} \frac{1}{3}\right)$, ont continué leur développement (cultures $\mathbf{I}-5$ en été I9I7) et leur contenu s'est vacuolisé. Dans les mêmes milieux, les algues provenant d'une solution plus nutritive (avec glucose ou peptone), ont rap:dement cessé de se multiplier (cultures 74 et 75 au printemps 1919) et se sont remplies de gouttelettes d'huile. Dans une série de cultures, faites au printemps 1918 avec glucose et galactose, les résultats ne correspondaient pas exactement à ceux, obtenus dans les mêmes concentrations pendant l'été I I 7. Nous avons une analogie à propos de la formation des stades Dactylococcus et Scenedesmus chez le S. acutus. ${ }^{44}$ Dans un certain milieu, les cellules isolées qui viennent d'y être transportées, donnent naissance à des colonies Scenedesmus. Mais, après y avoir séjourné un certain temps, elles produisent, dans le même milieeu, des chaînettes Dactylococcus. Le résultat d'une expérience ne dépend donc pas uniquement du milieu dans lequel elle est faite, mais aussi de l'état de nutrition et de la virulence du matériel d'inoculation. C'est là un fait bien connu en bactériologie, mais sur lequel les algologues n'ont pas, jusqu'à présent, porté leur attention.

Nous avons aussi vu que l'influence du glucose se fait sentir d'une manière plus ou moins intense, selon les autres circonstances de croissance. Le résultat d'une expérience avec glucose doit donc être influencé par la vitesse du développement de l'algue. Celle-ci dépend de la virulence du matériel d'inoculation, de la lumière, de la température etc. Si, par conséquent, on observe de petites différences entre les résultats d'éxpériences répétées, il ne faut ni les attribuer à une sorte de périodicité mystérieuse, ni à un changement de nature de l'algue. Elles s'expliquent facilement par une série de circonstances qu'il est difficile ou impossible d'éliminer, et qui font que les résultats suivent la courbe de probabilité.

\section{Nécessité de la création d'une station centrale d'algues en culture pure.}

S'il n'est pas toujours facile, de répéter exactement une expérience à partir de la même culture pure, il est souvent

44 Grintzesco, 246 (1902). 
presqu' impossible d'identifier avec certitude son matériel et de savoir, si on a vraiment affaire avec la même race qu'un autre auteur ( $\mathrm{Nakano} 1$. c. 27, $5 \mathrm{I}$ ). Il est par conséquent très difficile de dire, si toutes les formes décrites de l'Ankistrodesmus Braunii, avant l'introduction des cultures pures, appartiennerit vraiment à une même race. Smith, ${ }^{45}$ qui a cultivé un Scenedesmus acutus Meyen, ne l'a jamais vu former le stade Dactylococcus, tandisqu'il a isolé une race Dactylococcus qui n'a jamais donné naissance, dans ses cultures, à un Scenedesmus. Il en conclut que les observations de Grintzes co et $\mathrm{Chodat}$ reposent sur une erreur et qu'il y a toujours une différence spécifique entre Scenedesmus et Dactylococcus. Mais, à la même époque, Nakano 46 a obtenu, en concordance aveo Grintzesco, le stade Dactylococcus à partir de Scenedesmus, et vice versa. Nous devons en conclure qu'il existe plusieures races de Scenedesmus acutus, dont les unes forment plus facilement le stade Dactylococcus que d'autres; et qu'il peut aussi exister des Dactylococcus qui passent difficilement au stade Scenedesmus. Nous avons des analogies chez les plantes supérieures: Chez les Conifères, le stade Retinispora peut être plus ou moins fixé. Chez certains Philodendrons, la forme juvénile est représentée par un "stade Potos"; il y a des espèces, ${ }^{47} \mathrm{dont}$ on ne connaît que cette dernière morphiose.

Nous avons ajouté ces faits pour démontrer la nécessité de développer une station d'algues en culture pure, telle qu'elle existe par. exemple à l'Institut botanique de Genève. L'Association Internationale des Botanistes a donné son appui moral et matériel à la station des Champignons à Amsterdam. Il faut absolument qu'une institution analogue se fasse pour les algues. Un auteur qui aurait terminé un travail sur une espèce, enverrait un échantillon de son matériel à cette station centrale. Ces cultures seraient à la disposition de chaque auteur qui a un intérêt à travailler sur une race connue. Cela éviterait beaucoup de travail inutile et aiderait à éclaircir bien des questions de la physiologie et de la systématique des algues. Espérons que le temps de la paix facilitera la réalisation de ce voeu.

4s Smith, 432 (1916 I), et 1185 (1914 II).

46 1. c. p. 20.

47 Goebel, Organographie, I, p. 389 (1913). 


\section{Résultats.}

I. Dans les solutions très diluées, l'Ankistrodesmus Braunii forme des cellules isolées, fusiformes et vacuolisées.

2. Dans Detmer $\frac{1}{3}$, le chromatophore remplit la cellule.

3. Le Chlorure de Sodium, à partir d'une concentration de $\frac{\mathrm{N}}{30}$, ralentit le développement et favorise la formation de sporanges.

4. Le glucose, jusqu'à $\frac{\mathrm{N}}{12}$, accélère le développement; il augmente le polymorphisme d'autant plus, que les matières minérales font défaut. A $\frac{N}{6}$ de glucose, les cellules sont complètement rondes. A $\frac{\mathrm{N}}{3}$, la division est troublée, les cellules sont aberrantes et géantes. A $\frac{\mathrm{N}}{2}$, le développement et la division se font lentement, les formes sont régulières.

5. Il n'y a pas de parallèlisme entre l'augmentation de la concentration et l'apparition de cellules rondes.

6. Le galactose ralentit le développement et l'arrête à $\frac{N}{12}$.

7. Le Fer accélère le développement.

8. Le Manganèse ralentit l'assimilation.

9. La peptone ralentit le développement et l'arrête à $0.5 \%$. Elle est facilement supportée en présence de glucose et de galactose.

Io. On a observé les stades suivants et étudiẻ leur formation: cellules isolées, fusiformes, arrondies, formes chlorelloïdes, sporariges à spores rondes, arbuscules, étoiles, Dactylococcus.

II. Ces stades ne constituent pas de "réaction adéquate“ visà-vis du milieu, mais leur forme est déterminee par la nature de l'algue et leur apparition est conditionnée par des circonstances extérieures.

12. Des essais sur la vitesse d'immersion ont été faits.- Dans un milieu donné, les formes allongées tombent moins vite que les formes trapues. Dans un milieu plus visqueux, des. formes plus trapues peuvent. encore flotter.

13. Le résultat d'une expérience dépend, entre autre, de l'état: de nutrition et de l'âge du matériel d'inoculation (virulence).

I4. La création d'une station centrale d'algues en culture pure serait extêmement désirable. 


\section{Liste bibliographique.}

On a cité, dans cette liste, à part des travaux utilisés directement, les plus modernes, qui ne sont pas encore mentionnés par Rayss.

1892 Artari Atex.: Untersuchungen über Entwicklung und Syste-

matik einiger Protococcoideen. Bull. Soc. Impér. Scienc. nat. Moscou 1892, et Diss. Basel, I 892.

1914 Artari Alex.: Zur Physiologie der Chlamynomonaden, II.

Einige neue Versuche und Beobachtungen. Pringsh. Jahrb.

f. wiss. Bot. LIII, p. 527.

1894 (Borge, O.: Über Rhizoidbildung bei einigen fadenförmigen

Chlorophyceen. Nya tidnings actiebodags, vol. II.

I91 5 Brunnthaler Jos.: Protococcales. In A. Pascher, Die Süßwasserflora Deutschlands, Oesterreichs und der Schweiz, Heft 5, Jena.

1915 Buchheim A.: Der Einfluß des AuBenmediums auf den Turgordruck einiger Algen. Diss. Bern.

I894 I Chodat Rob.: Nouvelles recherches sur les Raphidium. Bibliothèque universelle. Archives des sciences physiques et naturelles, p. 2, Vol. XXXI, Lausanne.

1894 II Chodat Rob.: Matériaux pour servir à l'histoire des

Protococcacées. Bull. Herb. Boissier, page 585, Vol. II.

1895 Chodat Rob.: Matériaux... etc. ibid. page rog, Vol. III. 1902 Chodat Rob.: Algues vertes de la Suisse. Matériaux pour

la Flore cryptogamique Suisse, Vol. I, fasc. 3, Berne.

1909 Chodat Rob.: Etude critique et expérimentale sur le Polymorphisme des Algues. Genève.

1913 Chodat Rob.: Monographies d'Algues en culture pure. Matériaux pour la Flora cryptogamique Suisse. Vol. IV, fasc. 3, Berne.

1916 Chodat Rob.: Sur l'isogamie, l'hétérogamie, la conjugaison et la superfétation chez une algue verte. Archives d. Sciences phys. et natur. 4me période, Vol. XLI, p. 155. Genève.

1895 Chodat R. et Huber: Recherches expérimentales sur le Pediastrum Boryanum. Bull. soc. bot. Suisse. Livr. I, p. r. I893 I Chodat R. et Malinesco: Sur le polymorphisme du

Raphidium Braunii et du Scenedesmus caudatus Meyen.

Bull. Herb. Boissier, Vol. I, page 640, Genève.

1893 II Chodat $R$. et Malinesco: Sur le polymorphisme du

Scenedesmus acutus Meyen, ibid. Vol. I, page 184-190.

1912 Coltins: The green algae of North America, suppl. in

Tufts College Studies, Vol. III. 
I9I 6 Ducellier F.: Contribution à l'étude du polymorphisme et des monstruosités chez les Desmidiacées. Bull. soc. bot. Genève II. sér. Vol. VII, p. 75-I I8.

1902 Grintzesco Jean: Recherches expérimentales sur la morphologie et la physiologie du Scenedesmus acutus Meyen. In $R$. Chodat, Travaux du Laboratoire de Botanique, 6me Sér. I fasc.

r9I9 Großmann Emanuel: Schwebefähigkeit und Koloniebildung einiger Scenedesmaceen, Referat gehalten an der Versammlung der schweizer. bot. Ges. in Basel, Frühjahr 1919. Le traveil complet va paraître.

rgl 2 Hoffmann-Grobéty A.: Contribution à l'étude des Algues unicellulaires en culture pure. Bull. soc. bot. Genève, $2^{\text {met }}$ sér., Vol. IV.

I9I I Issatschenko B.: Über Polymorphismus bei Stichococcus bacillaris, in Scripta Botanica, fasc. XXIX, Petrograd.

I9I 4 Jollos Vict.: Variabilität und Vererbung bei Microorganismen. Zeitschrift für induct. Abstammungslehre, XII.

I 88 I-85 Klebs Georg: Über Organisation einiger Flagellatengruppen. Untersuch. aus d. bot. Inst. Tübingen.

I896 Klets Georg.: Die Bedingungen der Fortpflanzung bei einigen Algen und Pilzen, Jena 1896.

r9I 4 Küfferath H.: Contribution à la physiologie d'une Protococcacée nouvelle, Chlorella luteo-viridis Chod.; Recueil de I'Institut botanique Léo Errera, Vol. IX p. I I3-3I9.

I 849 Kützing: Species algarum.

I916 Kuwada Y.: Some peculiarities observed in the culture of Chlamydomonas. Bot. Magaz. Tokyo, XXX, p. 347-358. I 916 Lieske R.: Serologische Studien mit einzelligen Grünalgen. Sitzungsber. Heidelberger Akad. Math. Nat., pas vu. voir le réferat dans Zeitschrift für Botanik, I916, p.694.

I9 8 Limberger A.: Úber Reinkultur der Zoochlorella aus Euspongilla lacustris und Castrada viridis Volz. Anz. Kais. Akad. d. Wiss. Wien p. 200-20I, et Sitzungsber. Kais.

Akad. d. Wiss. Wien I, CXXVII, p. 395-412, pas vu.

I9I7 Nakano H.: Untersuchungen über Entwicklungs- und Ernährungsphysiologie einiger Grünalgen. Journ. Coll. Sc. Imper. Univers. Tokyo, XL, 2 ; en allemand.

I9I7 Nakano H.: Über Reinkultur der Chlorophyceen. Bot. Mag. Tokyo XXXI, p. 5I-70, en japonais.

I9I 5 Naumann E.: Einige Reproduktionstechnische Gesichtspunkte betreffs photogr. Darstellung der Planktonformationen. Bot. Not. I9I 5, Nr. I. 
I9I 5 Prat S.: Algenernährung, Biologické Listy; IV, p. 3 Io; pas vu, voir Bot. C. Bl. CXXXIII p. 39.

I9I 5 Rayss $T$.: Le Coelastrum proboscideum. Etude de planctologie expérimentale. Thèse, Genève; paru aussi dans Matériaux pour la Flore cryptogamique de la Suisse, ,Vol. V, fasc. 2; Berne.

rgr7 Reverdin Louts: Une nouvelle espèce planctonique, Raphidium spirochroma L. Rev.; Bull. soc. bot: Genève. $2^{\text {me }}$ sér. IX.

I9I I Richter Osw.: Die Ernährung der Algen. Monographien und Abhandlungen zur Internationalen Revue der.gesamten Hydrobiologie und Hydrographie, Bd. II, Leipzig.

I9I.3 Richter Osw.: Die Reinkultur und die durch sie erzielten Fortschritte vornehmlich auf botanischem Gebiet. Progressus rei botanicae, IV.

I9I 4 Schramm J.R.: Some pure culture methods in the Algae. Ann. Missouri. Bot. Garden, I, p. 23-45.

rgr4 Schramm J. R., A contribution to our Knowledge of the relation of certain species of grass-green Algae to elemantary nitrogen. Ibid. I, p. I57-184, voir aussi Bot. C. Bl. CXXXI, p. 653.

1916 Senn G.: Besprechung der Arbeit von T. Rayss über Coelastrum proboscideum. Zeitschr. für Botanik, Vol. VIII, p. 690.

19I4 I Smith G. M.: The Cell Structure and Colony Formation in Scenedesmus. Archiv f. Protistenkunde, Vol. XXXII p. $278-297$.

1914 II Smith G.M.: The organization of the colony in certain fourcelled coenobic algae. Trans. Wisconsin Acad. Sci. Arts and Lett. XVII, Pt. 2 ; I 165-1 220.

I.916I Smith G.M.: A monograph of the algae genus Scenedesmus based upon pure culture studies. ibid., XVIII p. $422-530$.

1916 II Smith G. M.: Cytological Studies in Protococcales I, II. I Zoospore Formation in Characium Sieboldii A. Br. Ann. of Botany, XXX, p. 451 .

II Cell structure and Zoospore Formation in Pediastrum Boryanum (Turp.) Menegh. ibid. 469.

I9I 8 Smith G. M.: Cytological Studies in the Protococcales III. Cell Structure and Autospore Formation in Tetraedron minutum. Ibid. XXXII, p. 459. 
1906 Tanner-Füllemann: Sur un nouvel organisme du plancton du Schoenenbodensee, le Raphidium Chodati. Bull. Herb. Boissier II ${ }^{\text {me }}$ sér. VI, p. I56.

I917 Vischer W.: Versuche mit Raphidium Braunii (vorläufige Mitteilung). Verhandl. d. schweiz. natf. Ges.; 99. Jahresversammlung in Zürich. II. Teil, p. 229. Aarau r9r8.

I9I6 West G.S.: Algae, Vol. I. in Cambridge Botanical Handbooks.

\section{Explications des planches hors texte.}

Planche $I$.

1) Culture 1; chromatophore très petit; cellules vacuolisées, transparentes.

2) $\quad 4$; chromatophore vert, remplissant la cellule.

3) n 12; chromatophore vert, avec échancrure au milieu.

4) " 34; cellules inégales.

5) $\quad 36$; au milieu, des cellules en forte multiplication.

6) $\rightarrow 38$.

7) $" 39$.

8) $\quad n \quad 46$.

9) $\rightarrow 48$.

Planche 11.

1) Culture 49; les cellules sont arrondies et forment souvent des colonies chlorelloüdes.

2) $\quad 52$; on voit les deux pointes incolore et le chromatophore vert foncé.

3) $\quad$ 55; comme 2 .

4) $n$ 9; les cellules se sont fixées sur un dépôt minéral.

5) " 33; multiplication et formation d'un arbuscule; on voit, à droite le reste la membrane de la cellule mère; à gauche elle est à peine visible en $t$.

6) $\quad 98$; du fond de l'éprouvette.

7) $n$ 98; flocon nageant; on remarque les restes des membranes qui restent accrochés.

8) $\quad$ 92; du fond de l'éprouvette.

9) $\quad 94$; comme 8 .

10) "97; belles colonies chlorellö̈des.

11) " 63; cellules géantes, multinucléées? La cellule à droite écrasée par la lamelle. 

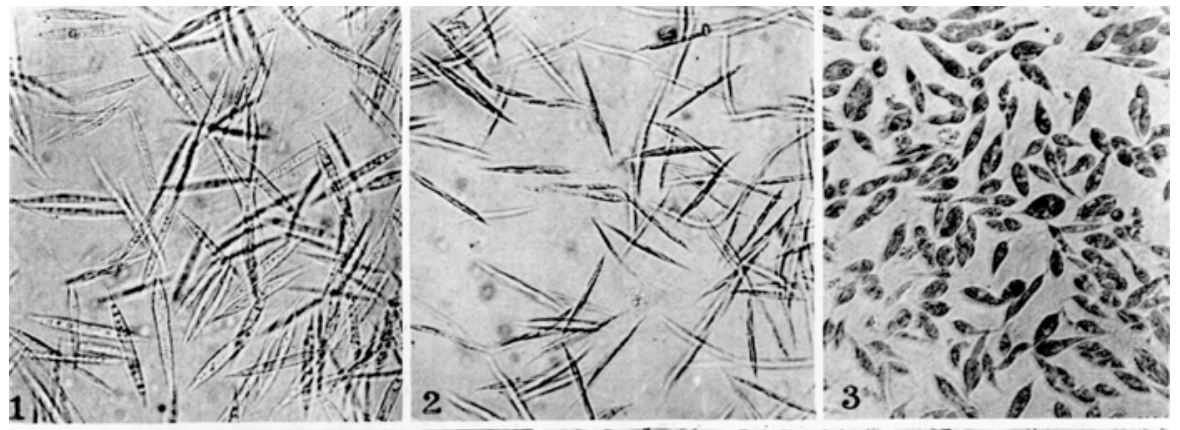

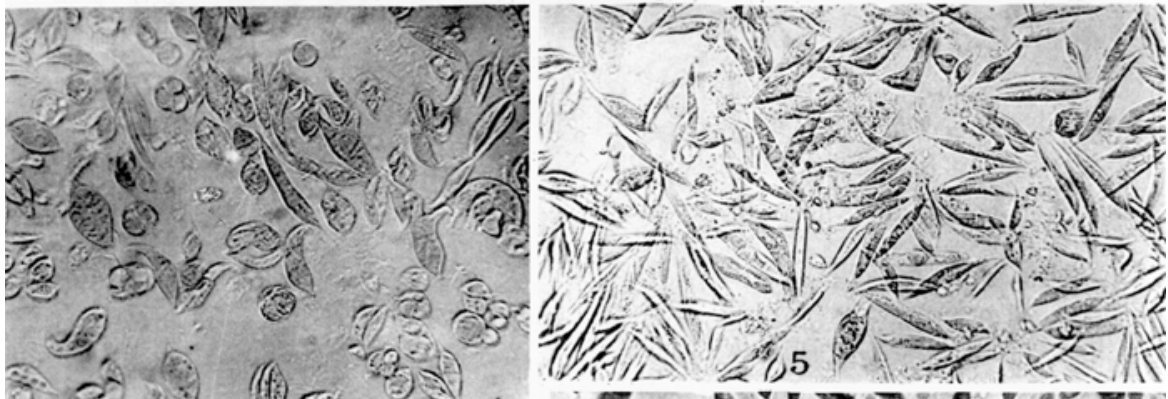

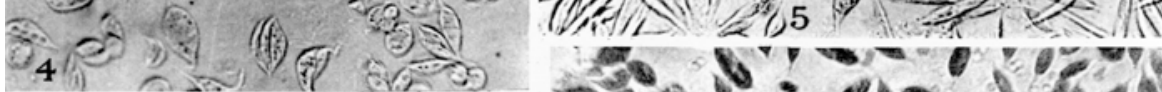

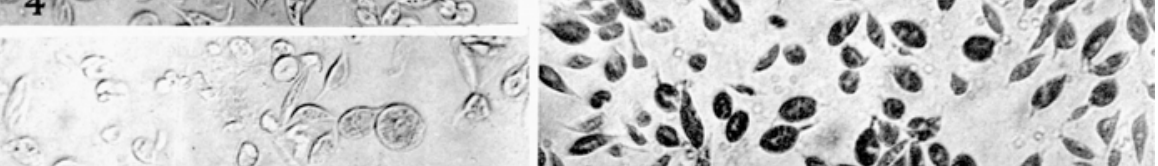

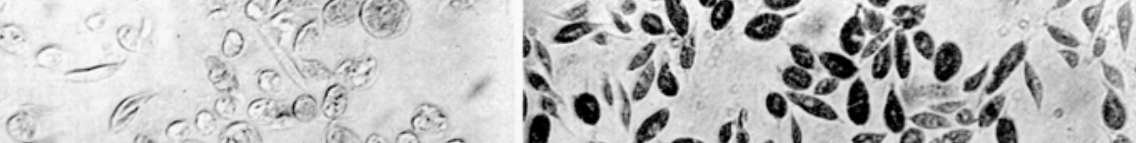

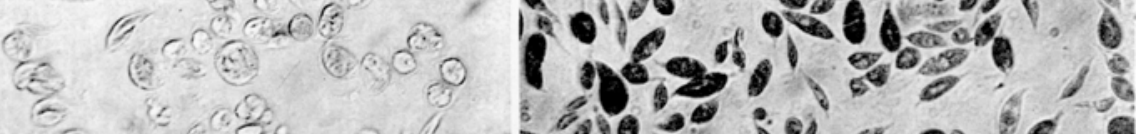
cera

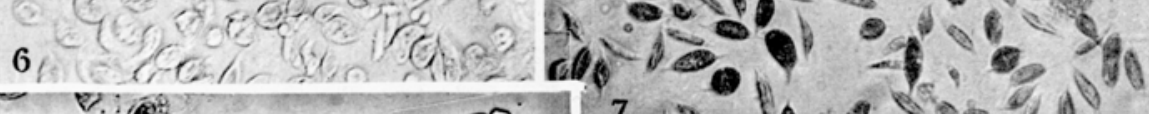

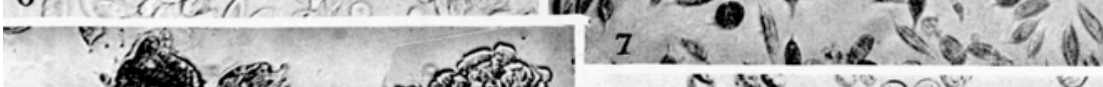

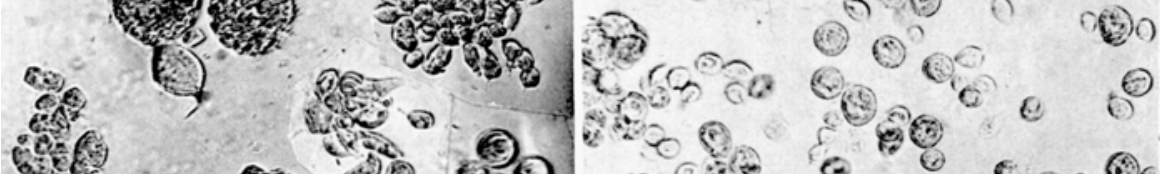

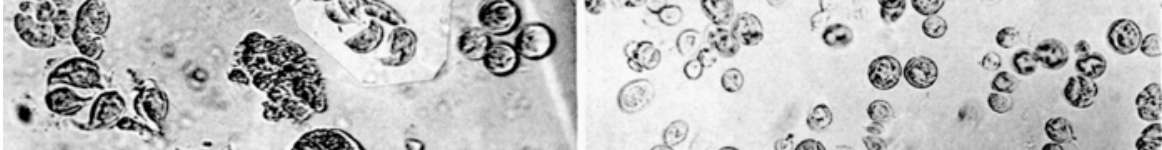

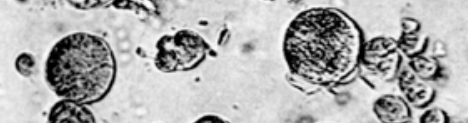

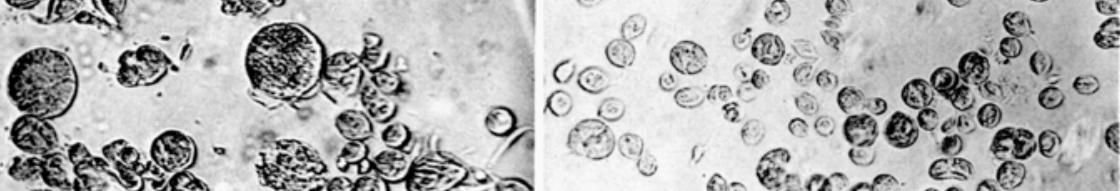
(2)

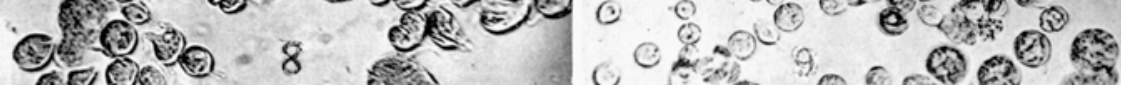




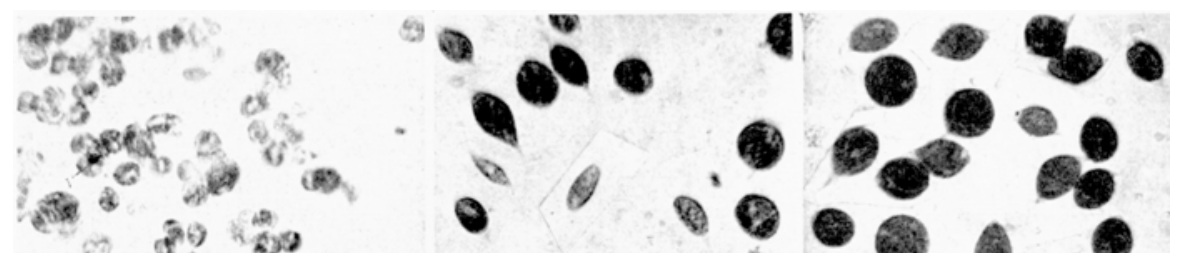

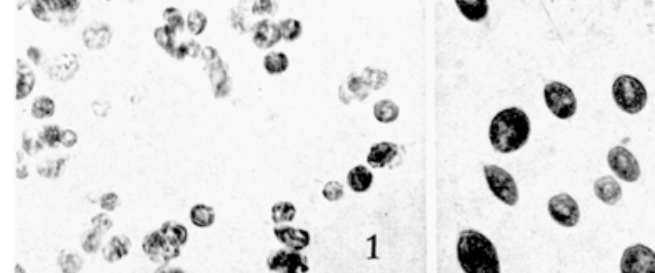
2. 8 $0:-0$ intil

- ${ }^{8} \mathrm{O} \mathrm{Oos} \mathrm{g}^{3}$
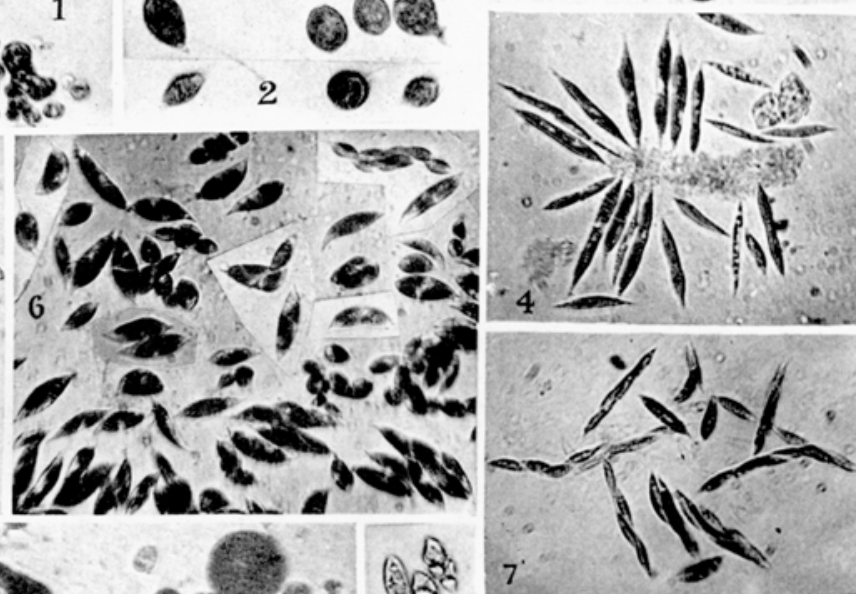
beas. ast

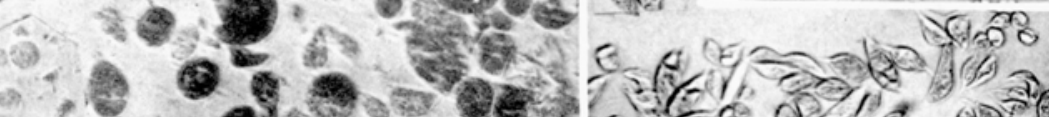

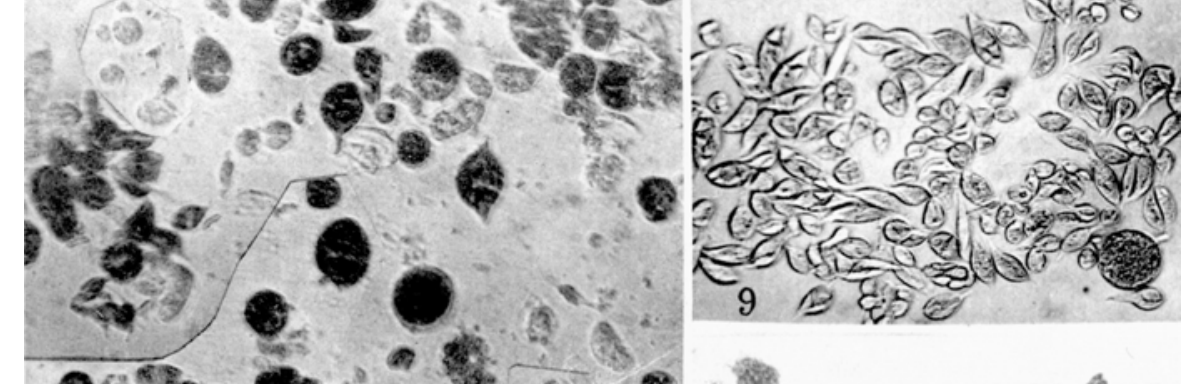

- sing is of

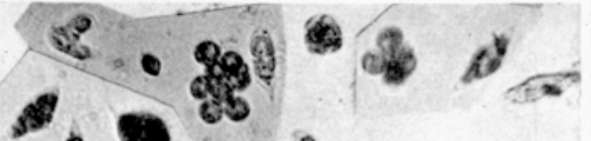

- ${ }^{2}$.

- $0^{2}$ ,
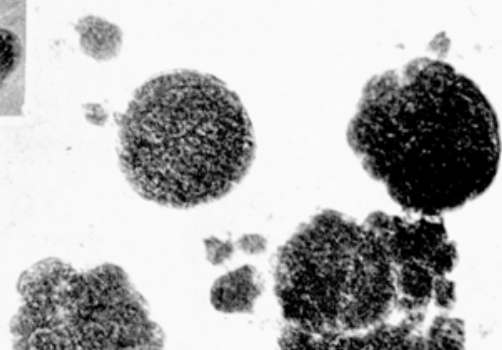

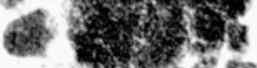
gin)

(⿻)丨

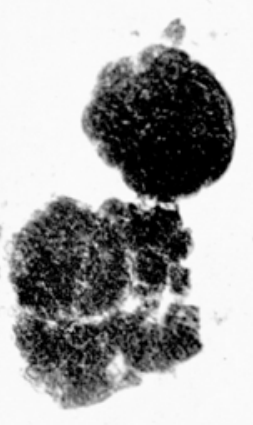

